Motu Working Paper 21-10

\title{
Monitoring Economic and Social Rights in the Pacific
}

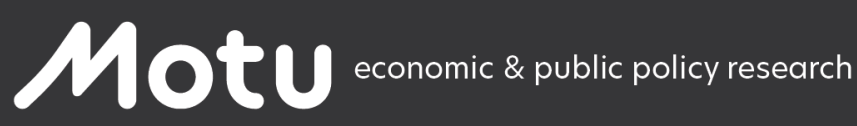

Susan Randolph, Shaan Badenhorst, John Stewart

August 2021 


\section{Document information}

\section{Author contact details}

Susan Randolph

Human Rights Measurement Initiative Economic and Social Rights Lead \&

Associate Professor Emerita, Department of Economics, University of Connecticut

susan.m.randolph@gmail.com

\section{Acknowledgements}

We would like to thank all those at the Pacific Community (SPC) as well as attendees of the Human Rights Measurement Initiatives 2019 Co-Design Workshop in Auckland, who so generously gave of their time and ideas. Special thanks go to David Abbott, Nilima Lal, Alison Culpin, Michael Sharp, Scott Pontifex, Ashley Bowe, and Kaobari Matikarai at SPC. We also thank the New Zealand Ministry of Foreign Affairs and Trade (MFAT) for its generous funding of this project.

\section{Disclaimer}

While we acknowledge the contributions of individuals at SPC, MFAT and attendees at HRMI's 2019 Workshop, the views expressed, and conclusions reached herein are those of the authors alone.

\section{Motu Economic and Public Policy Research}

$\begin{array}{lll}\text { PO Box } 24390 & \text { info@motu.org.nz } & \text { +64 } 49394250 \\ \text { Wellington } & \text { www.motu.org.nz } & \\ \text { New Zealand } & \end{array}$

(C) 2021 Motu Economic and Public Policy Research Trust and the authors. Short extracts, not exceeding two paragraphs, may be quoted provided clear attribution is given. Motu Working Papers are research materials circulated by their authors for purposes of information and discussion. They have not necessarily undergone formal peer review or editorial treatment. ISSN 1176-2667 (Print), ISSN 1177-9047 (Online). 


\section{Abstract}

This paper explains and transmits a database and summarises the results of the Human Rights Measurement Initiative's (HRMI's) efforts to more fully integrate the 21 Pacific countries (excluding New Zealand and Australia) into HRMI's economic and social rights (ESR) metrics. It also explores the extent of bias in country scores when per capita Gross National Income (GNI) substantially exceeds per capita Gross Domestic Product (GDP) and the potential to expand coverage by substituting constant USD GDP data for constant PPP\$ GDP data. The report finds: (1) There are opportunities to substantially improve economic and social right enjoyment in the Pacific even in the absence of per capita income growth, (2) the range in economic and social right performance scores observed across the Pacific countries indicates there is considerable scope for countries to learn from each other what approaches hold promise - countries scoring poorly on one right can look to the policies and structures in place that have enabled other countries to achieve good scores on the same right, (3) in countries whose GNI substantially exceeds their GDP, HRMI's economic and social rights scores are upward biased, more so, the greater the gap between GNI and GDP, and (4) for those countries without PPP\$ per capita income data, the computation of a USD variant of HRMI's ESR metrics allows one to gain some insight, albeit imperfect, into their economic and social rights performance.

\section{JEL codes}

D63 (Equity, Justice, inequality, and other Normative Criteria and Measurement); I: Health, Education, and Welfare (I3: Welfare, Well-Being, and Poverty); K38 (Human Rights Law); O: Economic Development, Innovation, Technological change, and Growth (01: Economic Development, O2: Development Planning and Policy, O5: Economywide Country Studies); Y: Miscellaneous Categories (Y1 Data: Tables and Charts).

\section{Keywords}

Economic Welfare, Efficiency Equity, Well-being, International Law, Economic and social rights, human rights, Pacific countries, Oceania, economic and social rights performance, country studies, economic development, economic and social rights data.

\section{Summary haiku}

Quality of life

in Pacific countries can improve without growth. 


\section{Overview}

The purpose of this report is to transmit the data and summarise the results of our efforts to more fully integrate the 21 Pacific countries and territories into the 2020 update of the Human rights Measurement Initiative's (HRMI's) economic and social rights (ESR) database as commissioned by New Zealand's Ministry of foreign Affairs and Trade (MFAT). The report is divided into two main sections. The first section explains the data files while the second summarises the key findings regarding the performance of Pacific countries and territories on economic and social rights and investigates several issues related to the substituting alternative per capita income indicators for GDP per capita measured in 2011 PPP\$.

\section{Economic and social rights data for the Pacific}

The excel file accompanying this report, Dataset Assessing Economic and social Rights in the Pacific June 2020, includes four data sheets. The first sheet provides the codebook for the data sets," while the remaining three sheets provide the data using the "low- and middle-income country assessment standard", the "high-income assessment standard", and the input data, respectively. As its name suggests the codebook provides the necessary information to understand the data sets that are in the other sheets of the excel file. The codebook itself has three separate tables as explained below.

\section{A. HRMI's economic and social rights methodology}

Understanding the codebook and interpreting the data require a basic understanding of HRMI's methodology. A full description of HRMI's methodology can be found on HRMI's website here. HRMI's ESR metrics cover five rights, the rights to education, health, food, housing, and work. HRMI metrics include two different assessment standards given differences in data availability and the most pertinent right challenges facing countries at different income levels. As their names suggest, the low- and middle- income assessment standard is most relevant to low- and middle- income countries, while the high-income assessment standard is most relevant to high income countries. However, all countries are evaluated on both assessment standards to the extent the relevant data are available. Although HRMI's ESR metrics utilize socio- 
economic indicator values, such as the net primary school enrolment rate, HRMI's ESR scores differ from the indicator values. HRMI's ESR scores evaluate the extent to which a country is meeting its obligations to use the maximum of its available resources to progressively realize the economic and social rights articulated in the International Covenant for Economic, Social and Cultural Rights. They also can be thought of as measures of the extent to which countries are utilizing their available resources to enable all their people to flourish.

HRMI's ESR metrics evaluate country performance against two different benchmarks, the income adjusted benchmark and the global best benchmark. The income adjusted benchmark evaluates a country's performance relative to the best performance of countries at its per capita income level while the global best benchmark evaluates a country's performance relative to the best performing countries at any per capita income level. The income adjusted benchmark can be interpreted as a measure of the extent to which a State is using the maximum of its available resources to fulfil its ESR obligations as is consistent with Article 2 of the International Covenant for Economic Social and Cultural Rights. The global best benchmark can be interpreted as a measure of the extent to which a State has broadly met it obligations to ensure all people in the country enjoy the rights concerned.

HRMI's ESR metrics are high level metrics - they do not attempt to incorporate all aspects of each right rather they seek to broadly assess whether the most basic aspects of a right are fulfilled. So, for example, for the right to health, HRMI's ESR metrics incorporate measures related to child health, adult health, and reproductive health. Whenever possible, bellwether indicators, incorporating multiple aspects of a right are used. For example, for the right to food, we use the child stunting rate since normal growth requires both sufficient micro and macro nutrients. Additionally, if children are not getting enough nutritious food, given that parents tend to protect their children's nutrition, it is also likely that adults in the family are also unable to get sufficient nutritious food.

One other aspect of HRMI's ESR metrics needs to be noted. That is, since our focus is on the extent to which States are meeting their obligations, we need to compare rights enjoyment levels to those that would exist in the absence of any State provision. So, while we might argue that good sanitation facilities or good schools are unlikely to exist without State action to directly or indirectly provide the necessary infrastructure or ensure the structures are in place to enable people to access services through the marketplace, State intervention is not required to enable some level of food consumption or enable some people to enjoy good health. As such, performance is measured relative to the "natural minimum." The "natural minimum" is specified as the lowest enjoyment level observed in any country in the world over the past quarter 
century, or in the case where indicators reflect public goods provision, such as in the case of sanitation facilities that separate out and treat excreta, $0 .{ }^{1}$

Figure 1 below helps explain how HRMI's metrics are constructed and how they should be interpreted. We begin with a scatter plot of the percentage of children enjoying normal growth, our bellwether indicator of the right to food against per capita GDP for all countries in the world over the last few decades for which we have data. Per capita GDP is measured in constant (2011) PPP $\$$ to comparable across countries and over time. In figure 1 below, each dot shows a specific country's observation for a given year; four such country observations are identified by country name below. We then use econometric techniques to fit a curve to the outer boundary of the scatter plot. This is our achievement possibilities frontier. It shows the best performance that can be expected of countries at each different per capita income level and is our income adjusted benchmark.

Figure 1: Scatter Plot percentage of children that are not stunted against GDP per capita

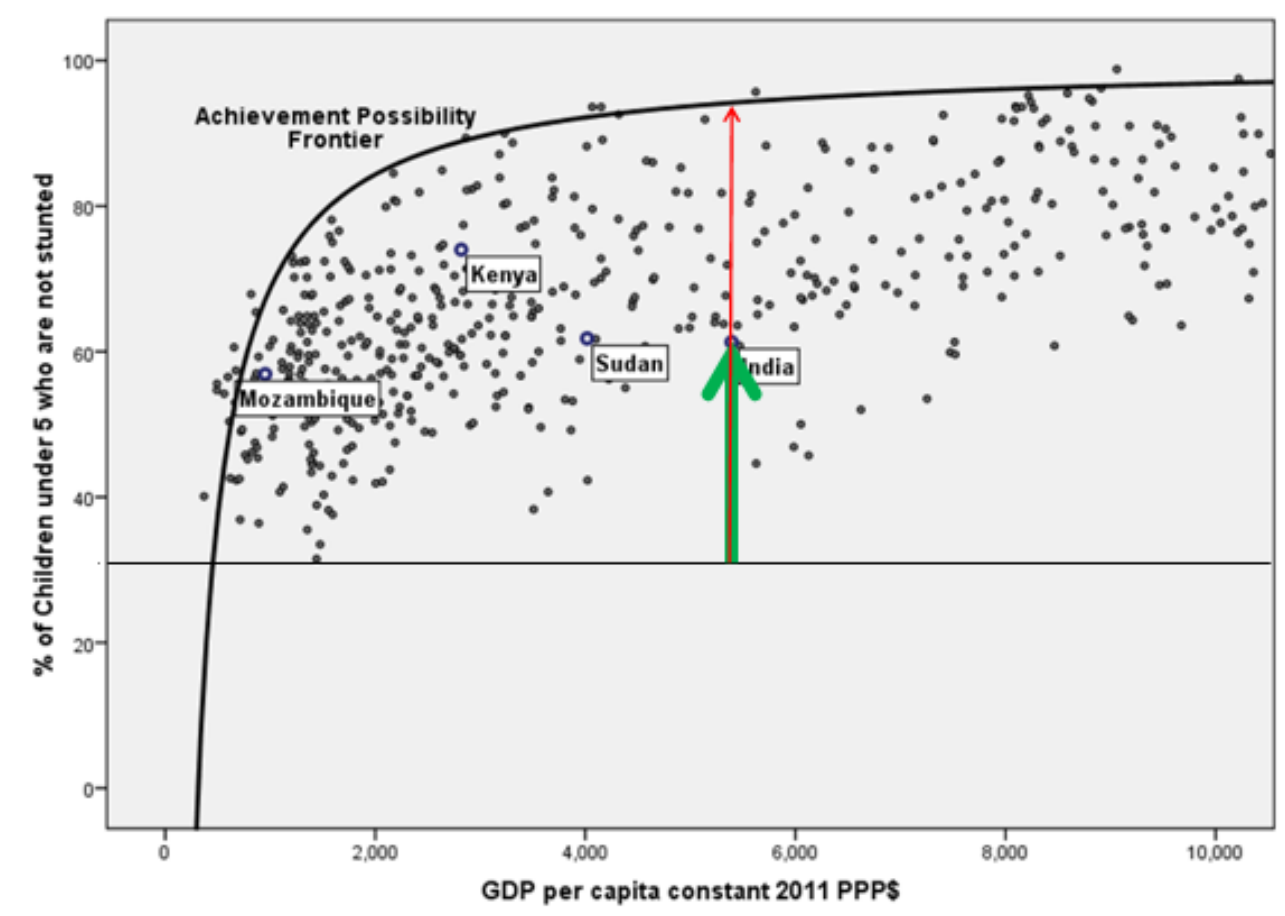

${ }^{1}$ In those cases where we set the natural minimum to 0 the lowest observed score in any country over the past several decades in fact approached or was equal to 0 . 
The maximum value of the achievement possibilities frontier shows the best performance of any country at any per capita GDP level which may or may not imply $100 \%$ of the population enjoys the right aspect concerned. The maximum value of the achievement possibilities frontier is the global best benchmark. We evaluate country performance relative to the "natural minimum" — the lowest indicator value observed in any country over the past several decades-our proxy for the indicator value reflecting what would occur in the absence of any State effort. The natural minimum is $31 \%$ in the case above as shown by the horizontal line at $31 \%$.

A country's income-adjusted score on the indicator is the percentage of the income adjusted benchmark achieved relative to the natural minimum. So in the diagram above, the income adjusted score for India is the height of the green arrow as a percentage of the height of the red arrow. India's global best score would be calculated as the height of the green arrow relative to the height of an arrow running from $31 \%$ to the maximum value of the frontier, in this case $97.7 \%$. India's global best score would be lower than its income adjusted score since the global best benchmark is above India's incomeadjusted benchmark. There is one other refinement that needs to be noted when calculating the scores for countries with more than enough income to achieve the global best benchmark but that fail to do so. A penalty is imposed on their score that is greater the lower is their raw indicator value and the greater is their per capita income.

Finally, Right scores are the average of the indicator scores related to the right while the Quality of Life score is the average of the Right scores.

\section{B. Codebook tables}

Rights and Right Indicators Table: The first column of this table provides our label for each of the five rights and each of the indicators in the data tables. The second and third columns use checkmarks to indicate which indicators are used for which assessment standards. It should be noted that some of the indicators are used for both assessment standards. The fourth column specifies the "natural minimum" value used in calculating HRMI's ESR metrics, while the fifth column specifies the maximum value of the indicator observed in any country over the past 20 years, the global best benchmark. The final column provides a brief definition of the indicator. The full definition is provided in the codebook on HRMI's website here. The list of right indicators provided here differs from that provided in our methodology handbook in two ways. First, we have omitted those indicators for which we were unable to find any data covering the 1997-2017 period for any of the 21 Pacific countries or territories. ${ }^{2}$ Second, in an effort

\footnotetext{
2 The 21 Pacific countries and territories concerned are American Samoa, Cook Islands, Fiji, French Polynesia, Guam, Kiribati, Marshall Islands, Federated States of Micronesia, Nauru, New Caledonia, Niue, Northern Mariana Islands, Palau, Papua New Guinea, Samoa, Solomon Islands, Tokelau, Tonga, Tuvalu, Vanuatu and Wallis \& Furtuna.
} 
to expand our coverage of the Pacific, three indicators are added as substitute, or as we call them, "sister" indicators for indicators that have limited coverage across the Pacific. These indicators are used in the construction of "Sister" Right Scores. The last column of the table also specifies the indicator that each sister indicator is a substitute for.

Right Score Components Table: A State's performance on a given right is the average of its scores on the indicators used to assess that right for the assessment standard concerned. The first column of this table specifies the right and assessment standard concerned while the second column of this table specifies the corresponding indicator scores (using the indicator labels) that are averaged to get the Right score for the assessment standard concerned. The indicator labels in red are indicators that are not available for any of the Pacific countries. As a result, the Right score for the assessment standard concerned cannot be calculated for the Pacific. Additionally, this table shows the indicator score components of the different "Sister" Right scores.

Variable/Term Names and Descriptions Table: The data files use a short-hand name for each of the variables/terms included. The left-hand column of this table provides the short-hand name that is the variable name you will see in the data files, while the righthand column explains what that variable name means. "IndicatorName" in each of the terms on the left-hand column changes depending on the indicator of concern from the Rights and Right Indicators Table. So, for example if you were concerned with the net primary enrolment rate, instead of "IndicatorName_MRYear" you would see NetPrimEnrol_MRYear, in data files in the accompanying excel spreadsheet. Thus, the value entered in the data table in that column would be the year of the most recent data on the percentage of the population that enjoyed at least improved sanitation facilities. If there are data on an indicator disaggregated by sex as well as for both sexes combined, the suffix_all, _fem,_or_mal is added at the end to tell you the data are for both sexes, females or males, respectively. If the data are only available for both sexes combined, then no suffix is added to the end of the variable name. The ESR metrics are calculated using three different measures of country resources, our standard measure, GDP per capita (2011 PPP\$), and two alternative measures, GNI per capita (2011 PPP\$), and GDP per capita (2011 USD. The variable "Group" indicates which measure of country resources has been used.

\section{The data sets}

Three data sets are included in the accompanying excel file. The data set on the second sheet in the excel file is called 'All Rights_Low \& Middle Income'. This data set includes all components for all the indicator, right, sister right, quality of life and sister quality of life scores: 
- Using the Low- and Middle- Income Assessment Standard,

- Using the Income Adjusted Benchmark

- Using the Global Best Benchmark

- All of the above using each of the three different per capita income measuresGDP per capita (2011 PPP\$), GNI per capita (2011 PPP\$), and GDP per capita (2011 USD).

The data set on the third sheet in the excel file is called 'All Rights_High Income'. This data set includes all components for all the indicator, right, and sister right scores:

- Using the High-Income Assessment Standard

- Using the Income Adjusted Benchmark

- Using the Global Best Benchmark

- All of the above using each of the three different per capita income measuresGDP per capita (2011 PPP\$), GNI per capita (2011 PPP\$), and GDP per capita (2011 USD).

It should be noted that it is not possible to calculate Quality of Life, Sister Quality of Life scores, or some of the Right scores for any of the Pacific countries using the HighIncome Assessment Standard because some of the indicators required to calculate the Right to education, the Right to food, the Right to housing, and the Right to work using the High- Income Assessment Standard are not available at this time for any of the Pacific countries.

The third data set on the fourth sheet in the excel file is called 'Pacific Input Indicator Values'. This data set contains all the raw indicator values for all years between 1997 and 2017 that we were able to compile for the 21 Pacific countries. In addition, the sources for each indicator-country-year entry are provided. The sources are quite diverse and in addition to the publicly accessible international data bases we use for the rest of the world, include:

- data from publicly accessible regional data bases such as SDD_SPC's Sustainable Development Goals data base, SDD_SPC's National Minimum Development Indicators data base,

- data from country reports on specific survey results or statistical reports

- data from country websites

- data calculated by HRMI from the above and/or from communications with SDD_SPC staff. 


\section{Economic and social rights in the Pacific}

Below we first highlight what our data show about economic and social rights in the Pacific using our standard indicator of country resources, Gross domestic Product (GDP) per capita measured in 2011 Purchasing Power Parity dollars (PPP\$). However, in several Pacific countries GDP is substantially lower than Gross National Income (GNI) measured in 2011 PPP\$. In the countries where this is the case, country scores will be biased upward and thus their performance will appear better than warranted. The second section below explores the extent of this bias. Both of the above indicators of country per capita resource capacity are measured in PPP\$ so as to standardize purchasing power comparisons across countries. However, the PPP\$ series is only available for 12 of the Pacific countries. A question arises as to whether it might make sense to approximate economic and social rights scores using a constant price USD series for those countries in the Pacific lacking PPP\$ data. This is the final topic we take up in this section.

\section{A. Economic and social right performance highlights}

Below we highlight the economic and social rights performance of the 12 countries for which GDP per capita data measured in 2011 PPP $\$$ are available. Our discussion is restricted to the results using the low-and middle- income assessment standard and the income adjusted benchmark. The low- and middle- income assessment standard is not only the most appropriate standard to use since only one of the twelve countries, Palau, is a high-income country, but also, data on many of the indicators used by the highincome assessment standard are not currently available for countries in the Pacific. Resource limitations impose important constraints on potential performance in the many of the Pacific countries, but to different degrees. The income adjusted benchmark takes this into account. We first take a look at individual country performance and then compare countries' performance on each of the five rights considered and on their overall quality of life score.

As discussed in our previous report, data availability on a number of the indicators we use in our global assessments to measure country performance on various rights and right aspects was quite limited. As a result, we have identified substitute "sister" indicators. Our standard indicator for access to consistent reproductive health services is the modern contraceptive prevalence rate. However, these data are not available for many of the Pacific countries and territories. One indicator that is widely available is the 
percentage of births that are attended by skilled health professionals. This indicator reflects access to reproductive health care at a single juncture-during childbirthrather than on a continuous basis. It discriminates best for countries at the bottom end of the income spectrum rather than the middle or upper ends and as such, we would expect country scores to be higher on this indicator as well as on the "sister" right to health score.

Second, our standard indicator for the right to food is the percentage of children under 5 that are not stunted. This is a bellwether indicator in that it captures whether children get sufficient calories, protein, and micro-nutrients. Additionally, if children are not getting enough healthy food, their parents are not likely to be getting enough healthy food either, since parents tend to deferentially ensure their children's nutrition. Information on the child stunting rate was not available for many of the Pacific countries. In its stead we include an indicator of whether households at least have access to a sufficient macro-nutrient, calories. The so-called "undernourishment" rate is an estimate of the percentage of the population below the minimum level of dietary energy consumption - calories. Our sister indicator, "Enough Calories" is 100\% - the undernourishment rate. It does not capture whether households have enough protein and other important micro-nutrients. As such, we would expect country scores to be higher on this indicator, than on our standard indicator, and accordingly the country's "sister" right to food score.

When examining country performance, we consider both country scores on our standard indicators of the different rights/right aspects and "sister" indicators for several of the rights/right aspects. We also construct a "sister" quality of life score. It differs from our normal quality of life score in that the "sister" indicators and corresponding "sister" right scores are substituted for our standard indicator and corresponding right scores.

Table 1 below shows which indicators are used in the construction of each of the 5 rights and sister rights using the low- and middle- income assessment standard. The table also shows the natural minimum indicator value, the global best benchmark (the per capita income level (2011 PPP\$) at which it is first feasible to reach to global best benchmark), and a brief description of the indicator. Separate frontiers were estimated for males, females and both sexes in the case of the adult survival rate and the child survival rate given that there is biological component to differences in survival rates. 


\section{Rights and \\ Right Indicators}

\section{Natural Minimum Value (\%)}

\section{Global \\ Best \\ Bench- \\ mark (\%) \\ GDP (2011 \\ PPP\$) \\ when \\ Global \\ Best \\ Reached}

Brief Description

5454
Percentage of population with access to water on premises Percentage of population with access to at least basic sanitation. Basic sanitation facilities include flush/pour flush to piped sewer systems, septic tanks or pit latrines; ventilated improved pit latrines, composting toilets or pit latrines with slabs.

Percentage of population living on more than $\$ 3.20$ (2011 PPP\$) per day
Right to Work NotAbsPoor
0
100
5769

7900

$\begin{array}{ll}100 & 5769 \\ 100 & 7900\end{array}$

The first set of graphs examines individual country performance. A second set of graphs then compares countries' performance on each of the five rights considered and on their overall quality of life score. When interpreting the graphs, it is important to keep in mind that the figures show the indicator, right and quality of life scores using the income adjusted benchmark, not the raw indicator values. These scores reflect how effectively a country is translating its resources into rights enjoyment. A country scoring $100 \%$ on an indicator means it is setting the benchmark for that income level; it is not generally enabling all people in the country to enjoy the right aspect measured. Its indicator score based on the global best benchmark (shown above in table 1) would have to be $100 \%$ as well for that to be the case. Table 2 below shows the per capita GDP (2011 PPP\$) in 2017 of the 12 Pacific countries for which we have PPP\$ data and whose scores are shown in the tables that follow. However, it should be kept in mind that the 2017 scores are calculated based on the most recently available raw indicator values and per capita GDP (2011 PPP\$) of the corresponding year. A maximum look back length of 10 years means both the indicator and GDP data values in the worst-case scenario could be for 2007. 


$\begin{array}{ll}\text { Country } & \text { GDP per capita (2011 PPP\$) } \\ \text { Fiji } & 9389 \\ \text { Kiribati } & 2025 \\ \text { Marshall Islands } & 3437 \\ \text { Micronesia, Fed. St. } & 2752 \\ \text { Nauru } & 13670 \\ \text { Palau } & 16239 \\ \text { Papua New Guinea } & 3957 \\ \text { Samoa } & 5904 \\ \text { Solomon Islands } & 2125 \\ \text { Tonga } & 5746 \\ \text { Tuvalu } & 3548 \\ \text { Vanuatu } & 2839\end{array}$

What constitutes good performance and what constitutes bad performance? Countries scoring $100 \%$ using the income adjusted benchmark are meeting their current obligations to fulfil the right or right aspect to the maximum of their available resources. They are also setting the standard for what is feasible at their per capita income level. Scores falling in the $95 \%$ to $100 \%$ are good to excellent. Scores falling in the $85 \%$ to $94.9 \%$ are fair. Scores between $75 \%$ and $84.9 \%$ are poor and scores below $75 \%$ are very bad.

\section{Country strengths and weaknesses}

We first look at individual country performance on each indicator, right, and overall and consider both our standard indicator scores and "sister" indicator scores. The bars' colours and patterns differ according to whether the standard (solid medium blue/grey) or sister (solid light blue/grey) indicator scores are being shown, whether the bar represents a right score (checked in the case the standard indicator scores are averaged into right scores, dotted in the case a sister indicator score is substituted for one of the standard indicators), and whether the quality of life score is shown (solid dark blue/grey in the case the standard right scores are averaged into the quality of life score and dotted dark blue grey when the sister right scores are substituted).

\section{Fiji: Indicator, right and quality of life scores}

Figure 2 shows Fiji's scores using the income adjusted benchmark and the low- and middle- income assessment standard. Looking first at the standard rights scores, Fiji's performance on the right to education overall is good. It is doing an excellent job of 
ensuring primary school enrolment but only doing a fair job of ensuring secondary school enrolment. Fiji's score on the right to health varies by component. It does a fair to good job of ensuring child health, but less well for adult health. Its score for reproductive health varies starkly depending on whether the standard or sister indicator for reproductive health is used. This suggests that while Fiji is doing an excellent job of ensuring women have access to health care during childbirth, consistent access to reproductive health care is seriously lacking. Fiji is doing a good job of ensuring its people have enough calories, although in the absence of data on child stunting it is unclear whether Fijians enjoy a diet with sufficient protein and micronutrients. While Fiji is doing a good job of ensuring people have access to improved sanitation, it is seriously deficient in ensuring people have access to an improved water source on their premises. Fiji has the potential to lift many more people out of absolute poverty even at its current per capita income level. 
Figure 2: Fiji indicator, right and quality of life scores: Income Adjusted Benchmark, Low- and MiddleIncome Assessment Standard

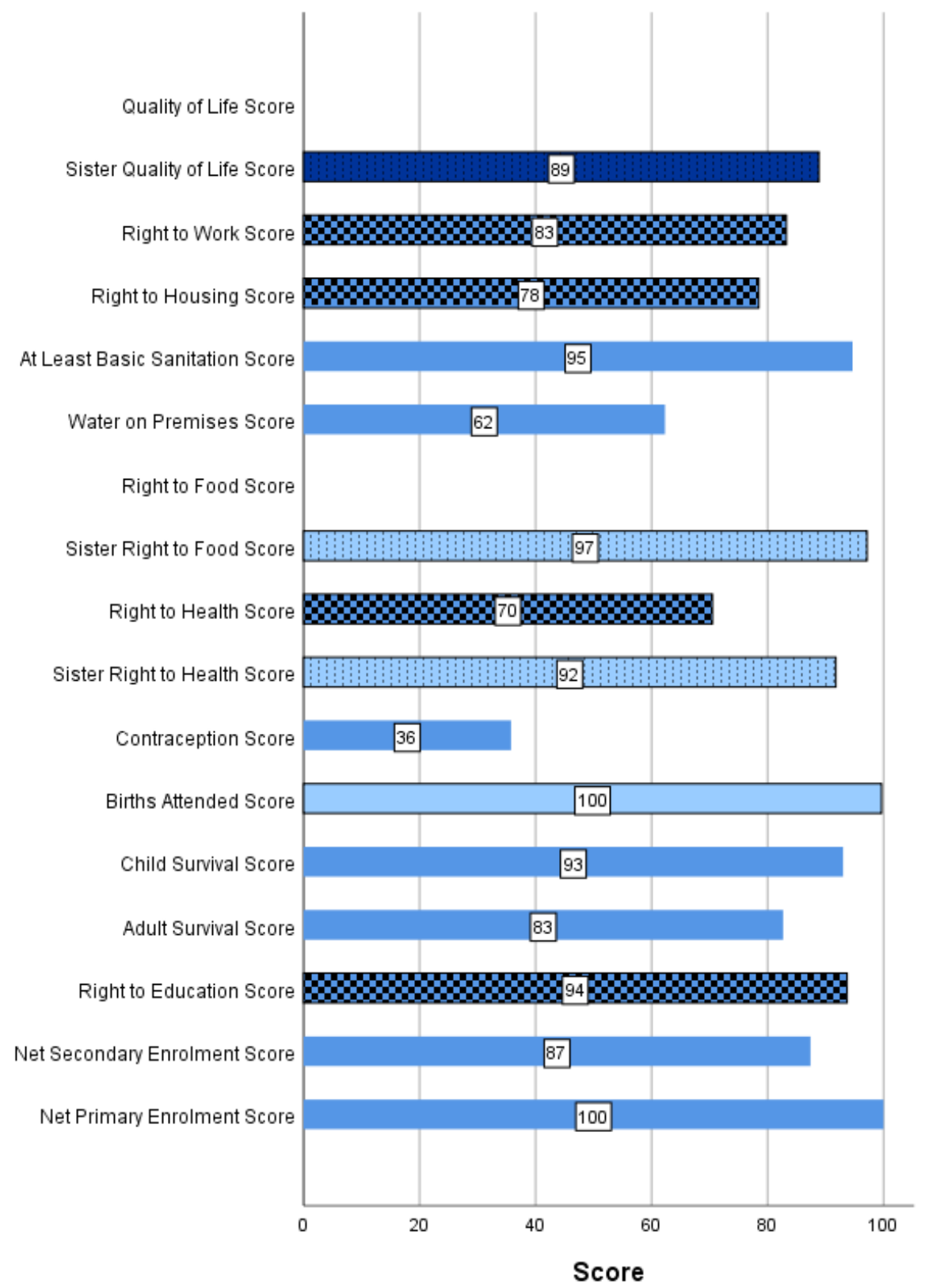

Federated States of Micronesia: Indicator, right and quality of life

\section{scores}

Figure 3 shows the Federated States of Micronesia's performance. Micronesia sets the benchmark for what is feasible to achieve regarding ensuring women have access to skilled health professionals for childbirth. It also does a good job of ensuring child survival and a fair job of ensuring adult survival given the resources it has. As a result, its score on the Sister Right to Health is good. Its score is only fair on the standard Right to Health given that its score reflecting consistent access to reproductive health care, the modern contraceptive use rate, is substantially lower than its score on providing women access to health care for childbirth. Micronesia also sets the benchmark for ensuring its 
people have enough calories although there is no data to determine whether it is doing equally well at ensuring that food has adequate protein and micro-nutrients.

Micronesia's greatest weakness Concerns ensuring children have access to schooling. There is tremendous scope to ensure more children have access to school, especially secondary school, despite Micronesia's income constraints.

Figure 3: Federated States of Micronesia indicator, right and quality of life scores: Income Adjusted Benchmark, Low- and Middle- Income Assessment Standard

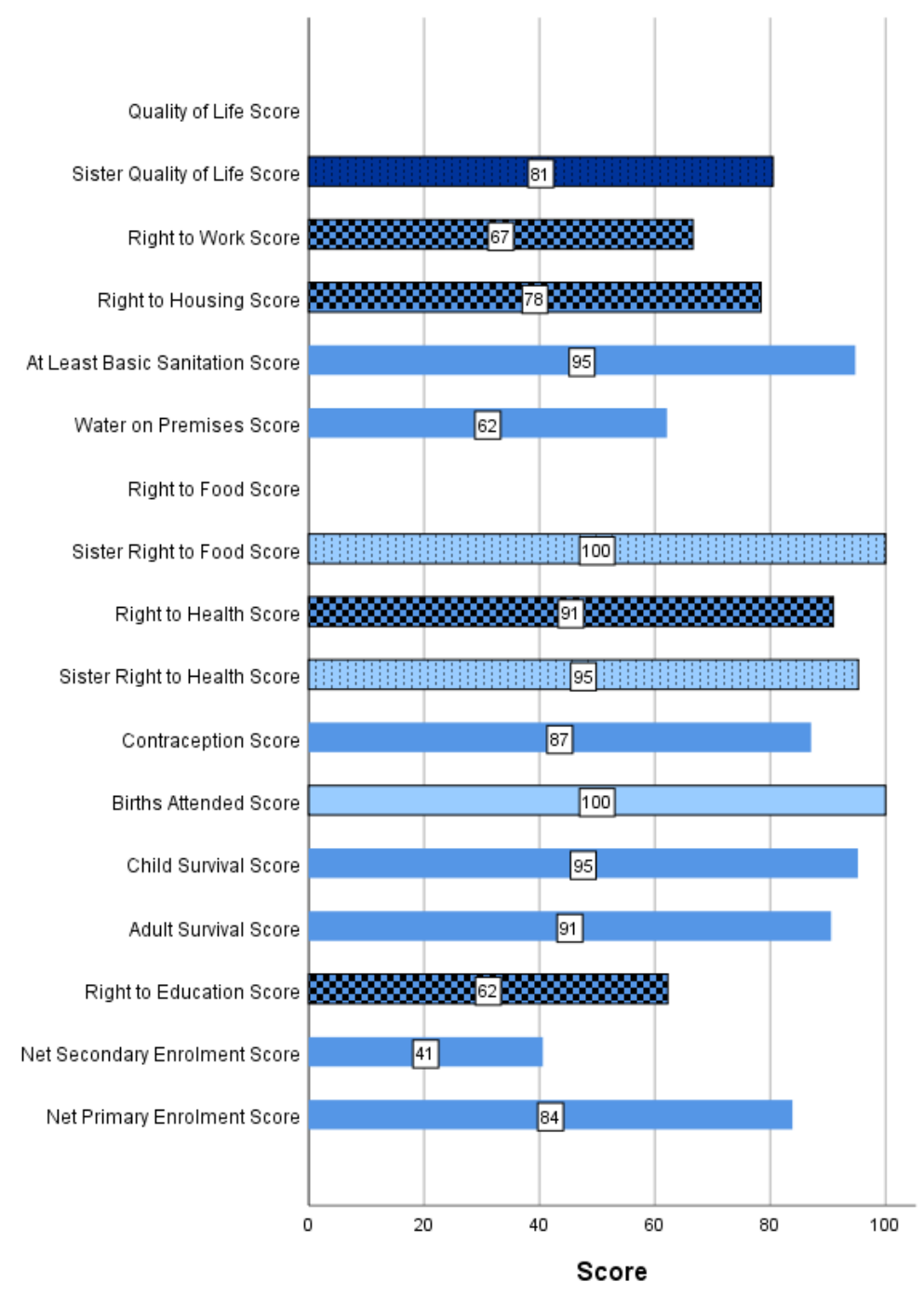

\section{Kiribati: Indicator, right and quality of life scores}

Kiribati sets the bar for its per capita income level when it comes to ensuring its people have enough calories (Figure 4). Kiribati is doing a fair job of ensuring the right to education although, even given its limited resources, more could be done. Similarly, it is doing a fair job of ensuring child and adult survival. It also does a fair job of ensuring women have access to skilled health professionals when giving birth. As a result, its Sister Right to Health score is fair as well. However, ensuring access to regular reproductive health care as reflected in the modern contraceptive use rate has posed a serious challenge and much, much more could be done here despite Kiribati's income 
constraints. Ensuring people have access to with essential infrastructure for good hygiene, similarly is an area Kiribati could do much better even in the absence of per capita income growth or foreign aid.

\section{Marshall Islands: Indicator, right and quality of life scores}

Figure 5 shows the results for the Marshall Islands. One of the Marshall Islands strengths is ensuring the right to water and sanitation, aspects of the right to housing. Although it sets the benchmark for ensuring people have enough calories at its per capita income level, the nutritional value of that food has not been sufficient to avoid much higher levels of child stunting that other countries at its per capita income level. When it comes to the right to health, the overall picture is mixed. Ensuring child health and survival is a strength but ensuring consistent access to reproductive health (as reflected in the modern contraceptive use rate) is its greatest weakness. When it comes to the right to education, much more could be done even within the constraints of the Marshall Islands' resources. 
Figure 4: Kiribati indicator, right and quality of life scores: Income Adjusted Benchmark, Low- and Middle- Income Assessment Standard

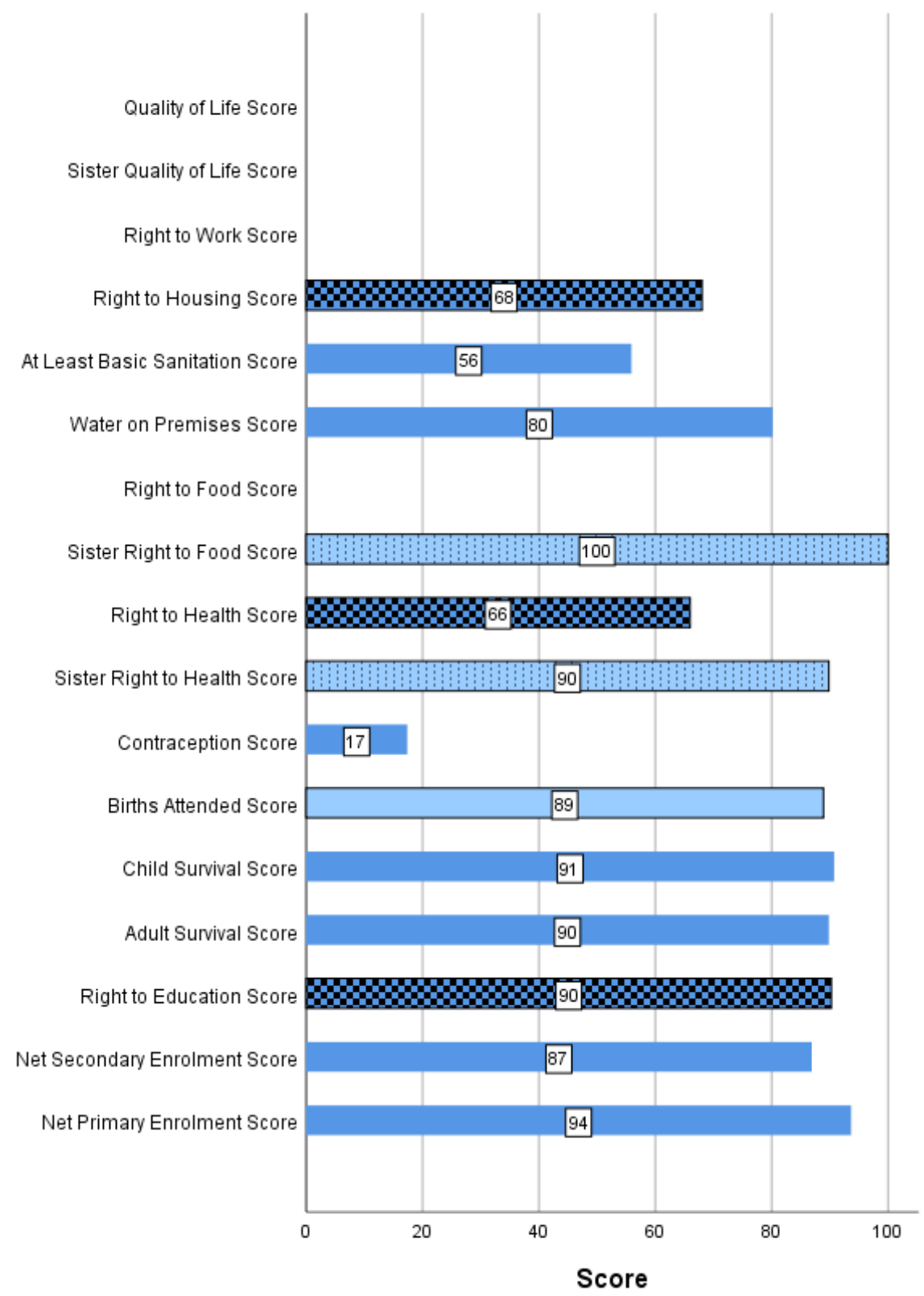


Figure 5: Marshall Islands indicator, right and quality of life scores: Income Adjusted Benchmark, Lowand Middle- Income Assessment Standard

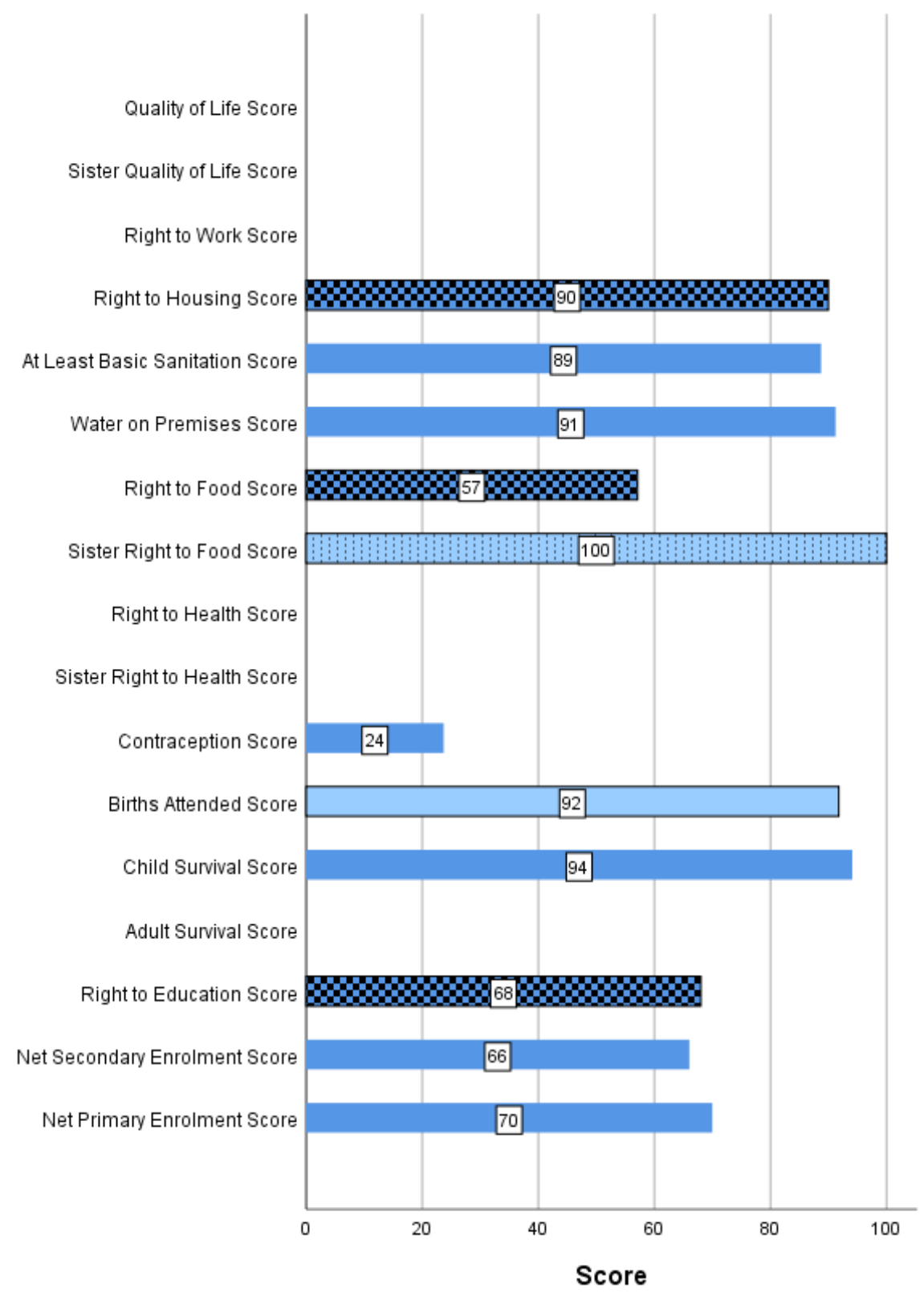

Nauru: Indicator, right and quality of life scores

Nauru's per capita GDP (2011 PPP\$) has been growing rapidly and is currently considerably higher than in the other Pacific countries for which we have PPP\$ data except Palau. Its ESR performance is quite mixed as figure 6 shows. With regard to the right to housing, it is doing a very good job of ensuring people have access to an improved water source on their premises, but quite badly on ensuring people have access to "basic" sanitation. Thus, its score on the right to housing is only poor. With regard to the right to food, like many of the other Pacific countries, it ensures its people 
have enough calories, yet performs poorly on ensuring children receive enough protein and micro-nutrients. Its scores on the components of the right to health vary widely: while it scores $100 \%$ on ensuring women have access to skilled health professionals for childbirth and fair on ensuring child health, it has significant weaknesses when it comes to ensuring adult health and on-going reproductive health.

Figure 6: Nauru indicator, right and quality of life scores: Income Adjusted Benchmark, Low- and Middle- Income Assessment Standard

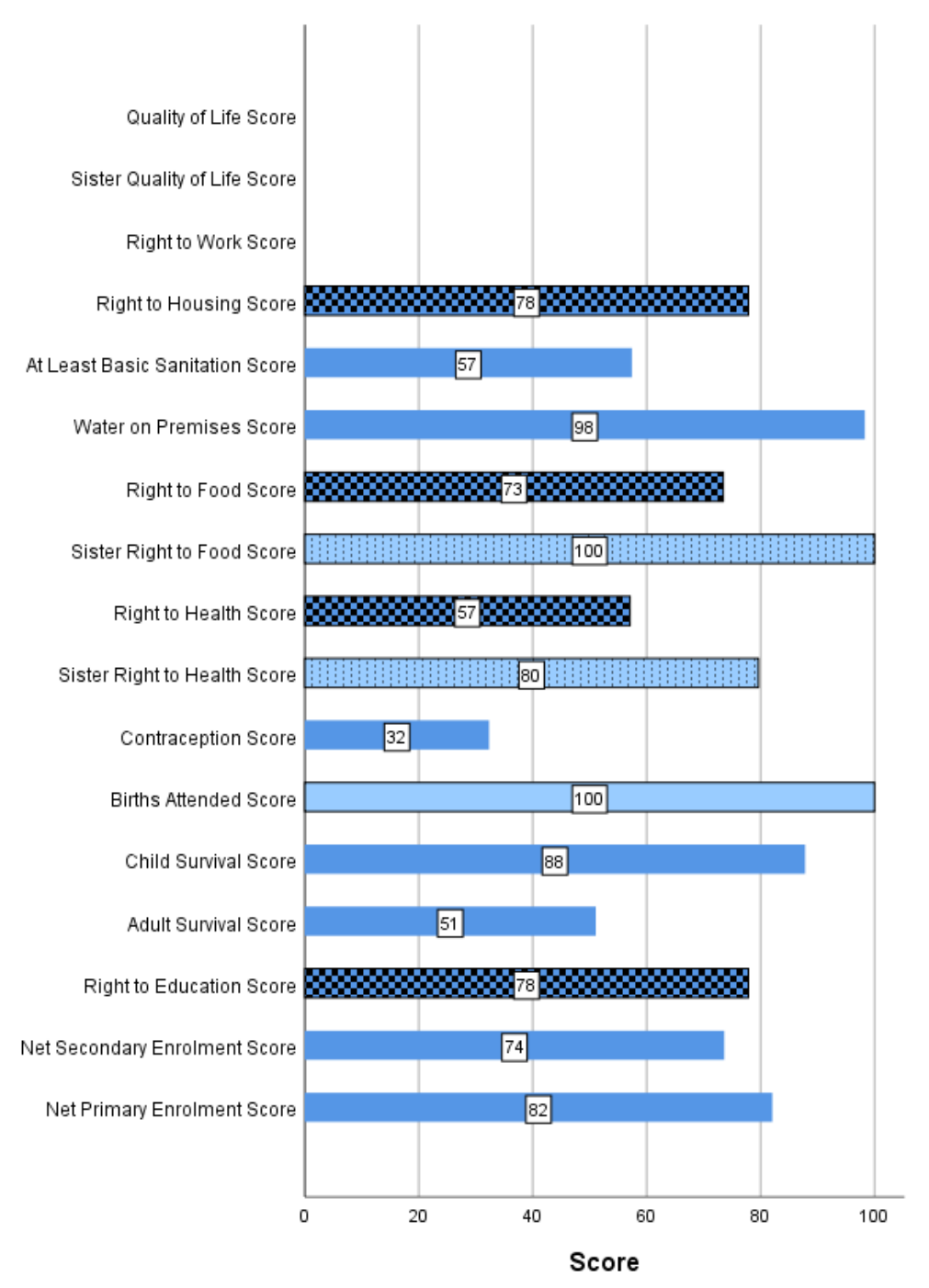

\section{Palau: Indicator, right and quality of life scores}

Palau is currently a high- income country (according to World Bank's classification) but prior to 2016 was classified as an upper- middle income country. Its performance on those indicators and right scores we are able to calculate is quite mixed as can be seen from figure 7. Palau has the top score on the right to housing. Like many of the Pacific countries, it ensures that all its people have enough calories to eat, but data are not available to enable us to learn whether the food meets all children's protein and 
micronutrient needs. Palau performs very badly on the right to school. In fact, it should readily be able to ensure that all its primary school aged children attend primary school and has the resources to enable twice as many of its children attend secondary school. Palau's performance on the right to health is mixed with regard to those aspects for which we have data. It rates a fair to good on child health and receives a top score when it comes to ensuring women have access to skilled health professionals during childbirth, but it scores very badly on our indicator of access to consistent reproductive health care-the modern contraceptive use rate.

\section{Papua New Guinea: Indicator, right and quality of life scores}

Papua New Guinea's economic and social rights performance is shown in Figure 8. Papua New Guinea sets the benchmark on ensuring people have access to sufficient food for countries with its per capita income level. However, as we have found for most of the other Pacific countries, when it comes to ensuring the available food optimally supports child growth, Papua New Guinea performs very poorly. There is scope to dramatically improve child growth even in the absence of per capita income gains. Overall though, Papua New Guinea does a fair job of ensuring child health and survival given its resources. The same cannot be said for the other rights and right aspects. Ensuring housing has the necessary infrastructure to enable good hygiene is an area where Papua New Guinea should be able to make dramatic gains even in the absence of additional resources. Overall, Papua New Guinea scores 45 out of 100 on our Quality of Life Metric, indicating scope to dramatically improve its people's well-being even in the absence of per capita income growth. 
Figure 7: Palau Indicator and Right Scores: Income Adjusted Benchmark, Low- and Middle- Income Assessment Standard

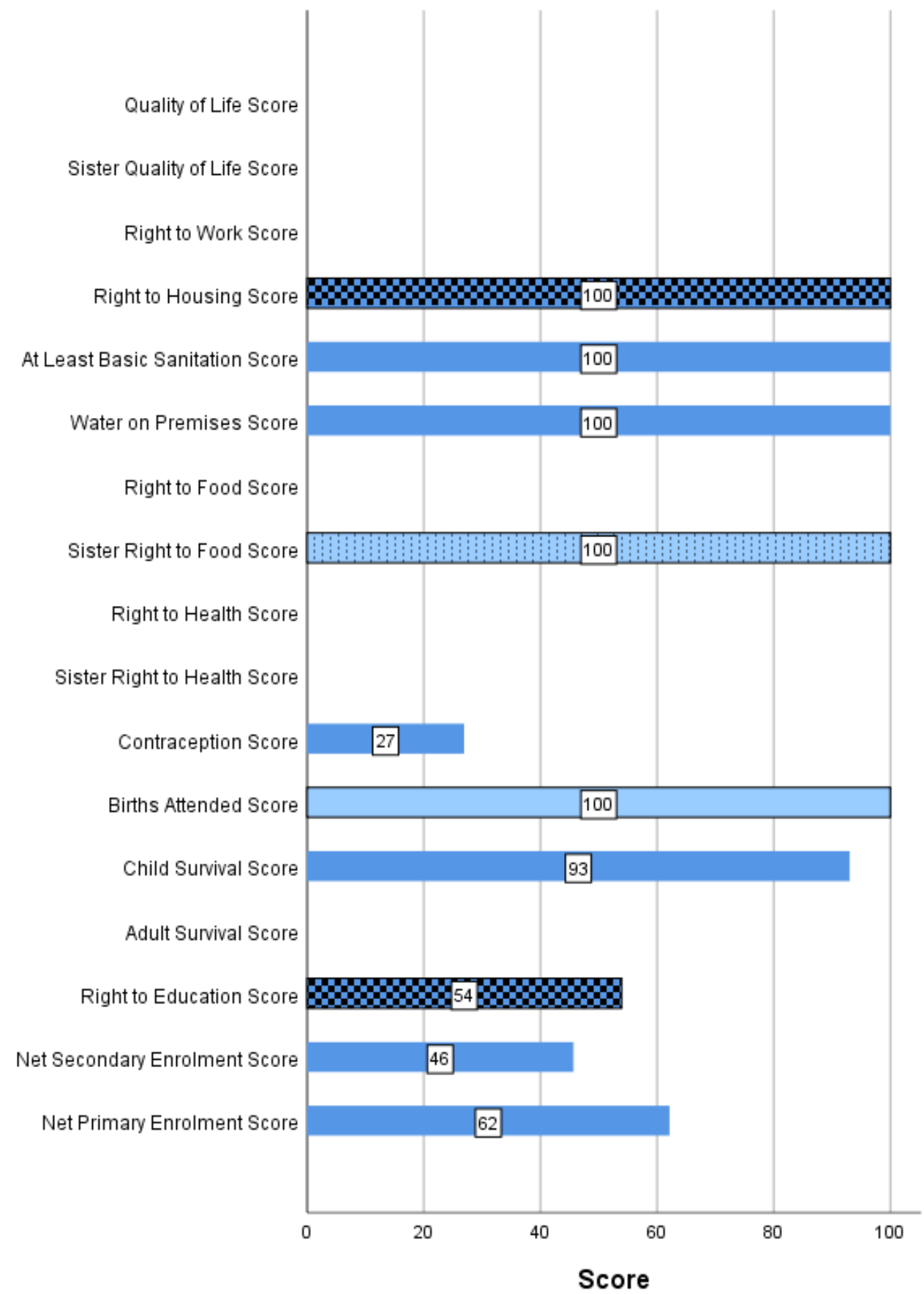


Figure 8: Papua New Guinea Indicator and Right Scores: Income Adjusted Benchmark, Low- and Middle- Income Assessment Standard.

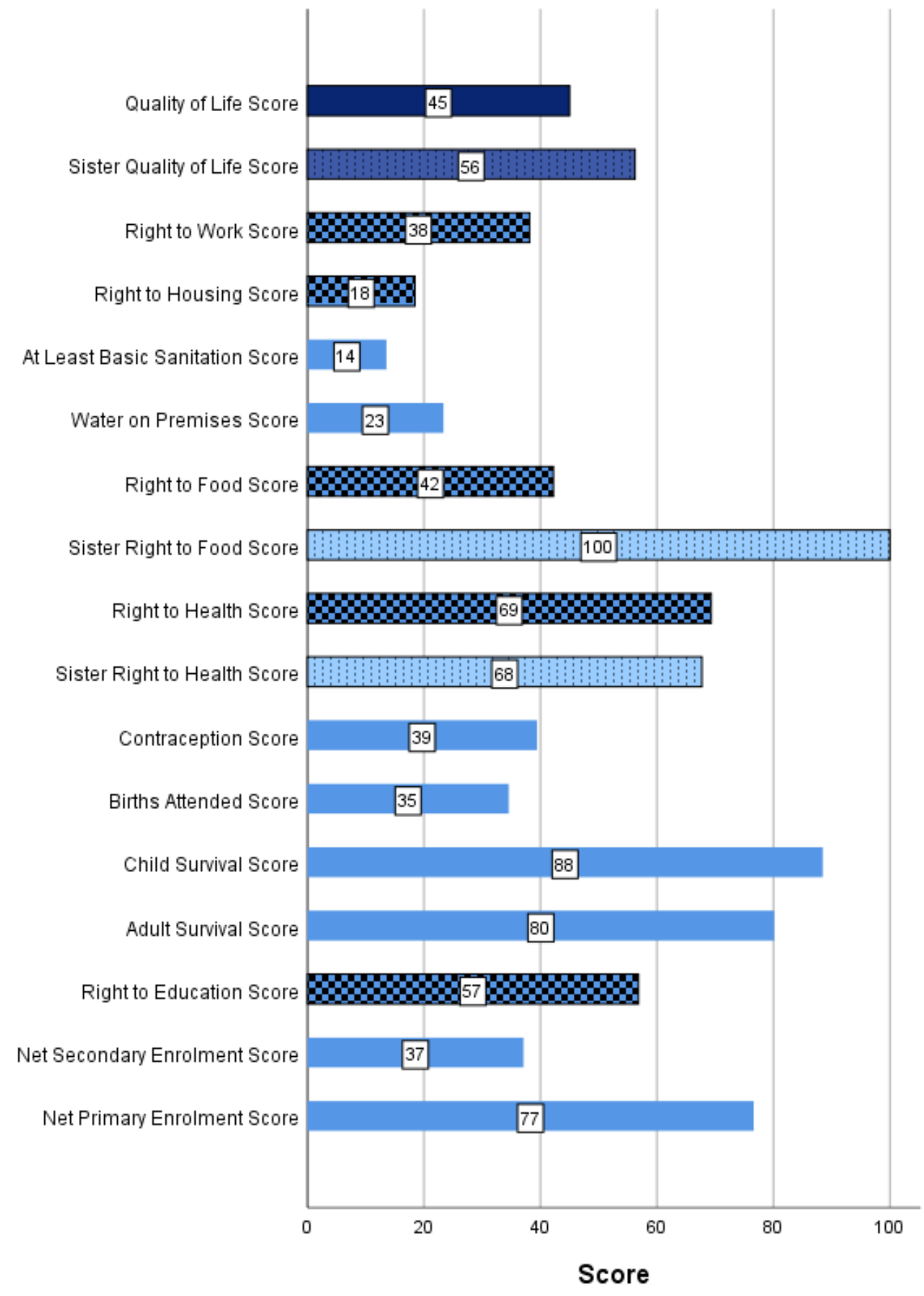

\section{Solomon Islands: Indicator, right and quality of life scores}

The Solomon Islands set the income adjusted benchmark for ensuring child health and survival at their per capita income. Their performance is nearly as good when it comes to ensuring adult health and survival. However, as is the case for many of the other Pacific countries, while their performance is good when it comes to ensuring reproductive health care for childbirth, their performance is very poor when it comes to 
providing consistent reproductive health care as is reflected in their very low score on modern contraceptive use. Also, like other Pacific countries, the Solomon Islands scores on the Right to Food and Sister Right to Food metrics indicates that it does a fair job of ensuring access to enough calories, ensuring access to sufficiently nutritious food remains a challenge. Even without per capita income growth there is tremendous scope to improve its people's ability to claim their rights to education, housing and work.

\section{Tonga: Indicator, right and quality of life scores}

Tonga's overall Quality of Life score is 87 indicating it is doing a fair job of translating its resources into improved well-being (figure 10). Tonga receives its lowest right score, 75 , on the Right to Health but this reflects widely varying performance on the different components of the Right to Health. Tonga scores 98 and 92 on child and adult health, respectively, but only 36 on our standard indicator of reproductive health. However, it receives a good score, 95, on the Sister Right to Health metric given its high score on one aspect of reproductive health, ensuring women have access to a skilled health professional during childbirth. Like most of the other Pacific countries, Tonga sets the benchmark for ensuring its people have enough calories, but in contrast to most of the other Pacific countries, Tonga has also done a good job relative to its resources of ensuring the nutritional value of the food supports optimal child growth. 
Figure 9: Solomon Islands Indicator and Right Scores: Income Adjusted Assessment Standard, Lowand Middle- Income Assessment Standard

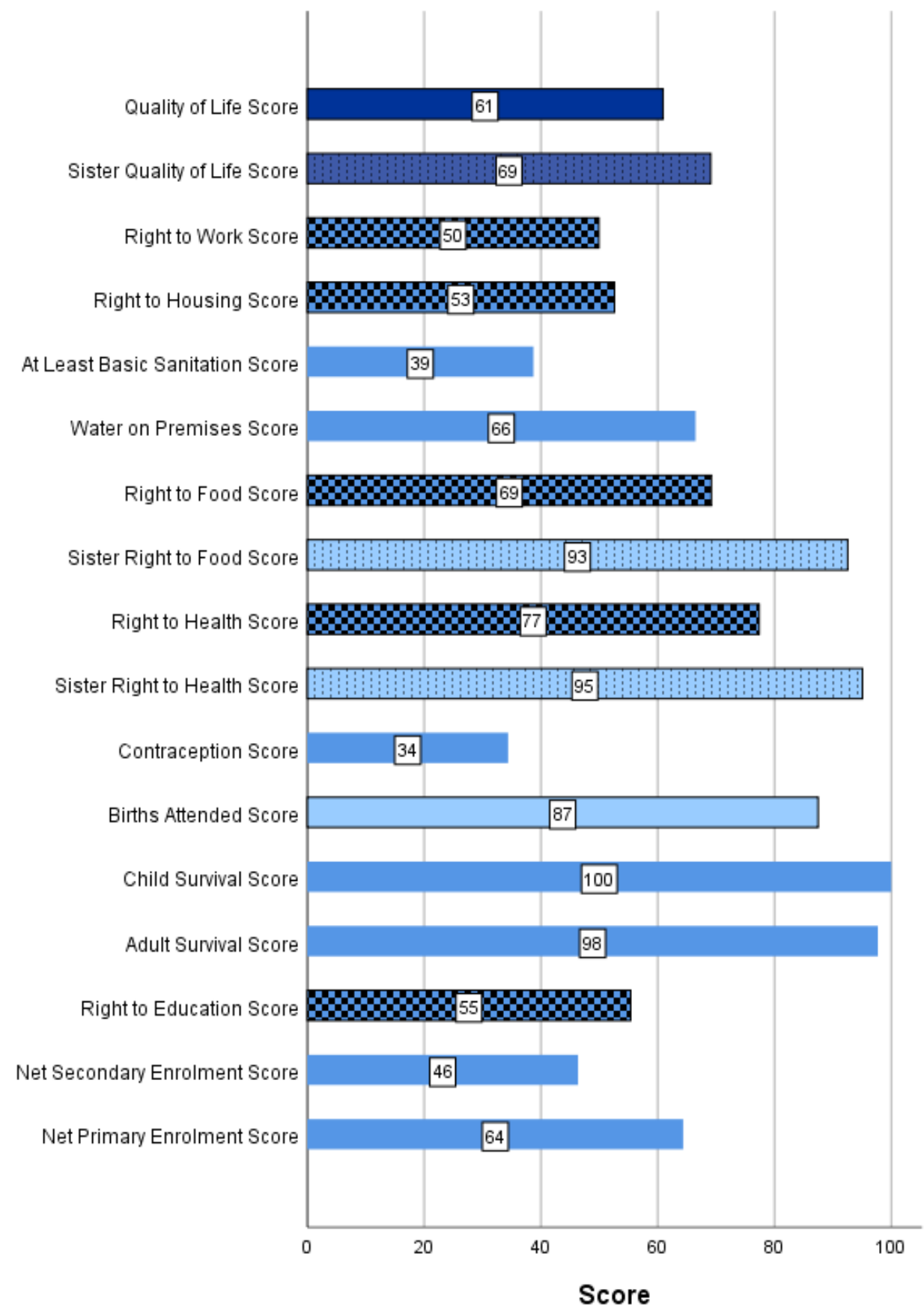


Figure 10: Tonga Indicator and Right Scores: Income Adjusted Benchmark, Low- and MiddleIncome Assessment Standard

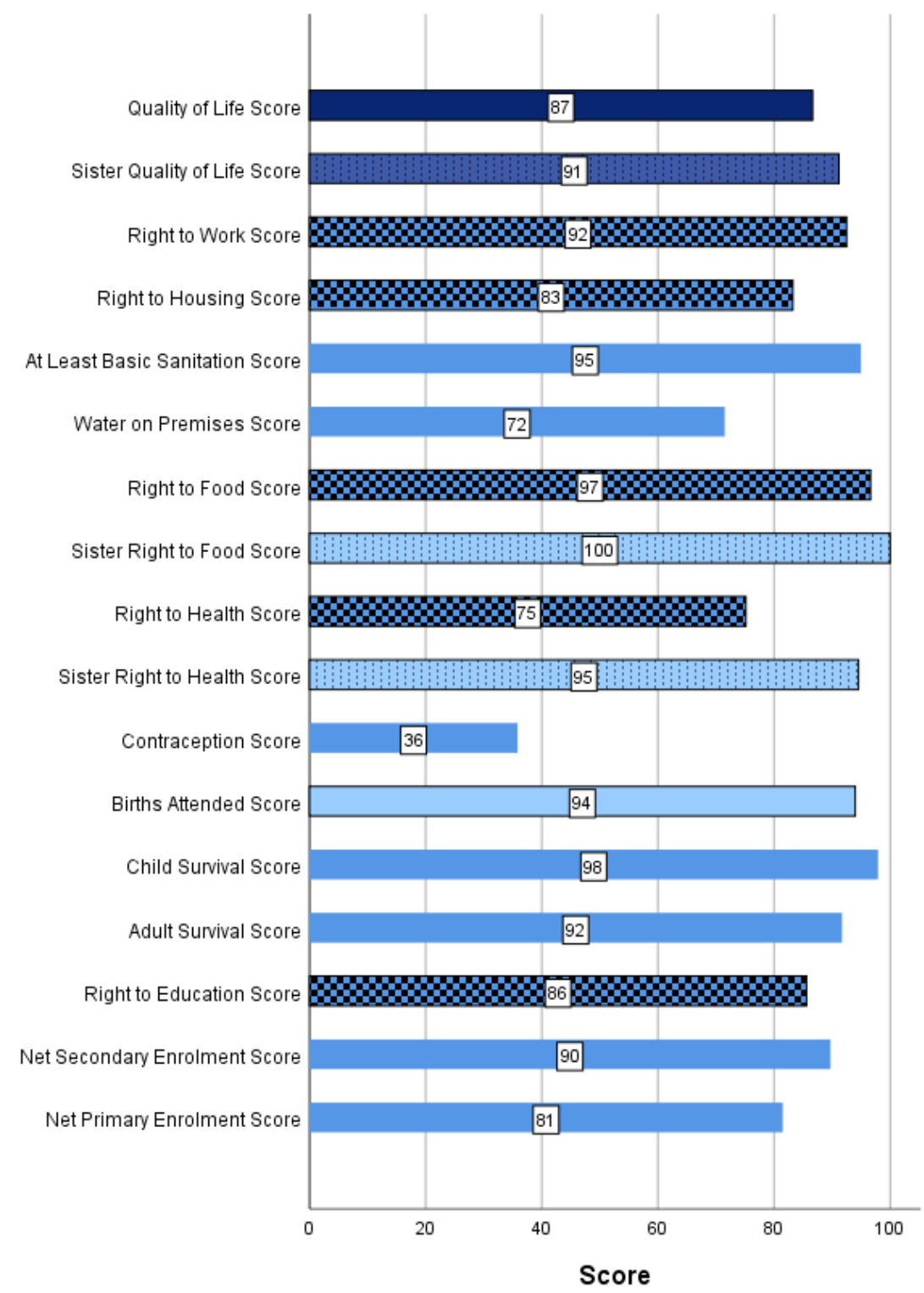

\section{$\underline{\text { Tuvalu: Indicator, right and quality of life scores }}$}

Tuvalu does a good job of ensuring child health and women's reproductive health during childbirth, but as is typical in the Pacific, consistent access to reproductive health care as reflected in women's access to modern contraception remains problematic as can be seen from figure 11. Like Tonga, it also does an excellent job not only of ensuring that people have enough calories, but also that the available food has sufficient protein and micronutrients. Among its available right scores, Tuvalu receives its lowest score, 83, on the Right to Education and here access to secondary school is the area needing the greatest attention; it receives a high score, 99, on ensuring universal access to primary school. 
Figure 11: Tuvalu Indicator and Right Scores: Income Adjusted Benchmark, Low- and MiddleAssessment Standard

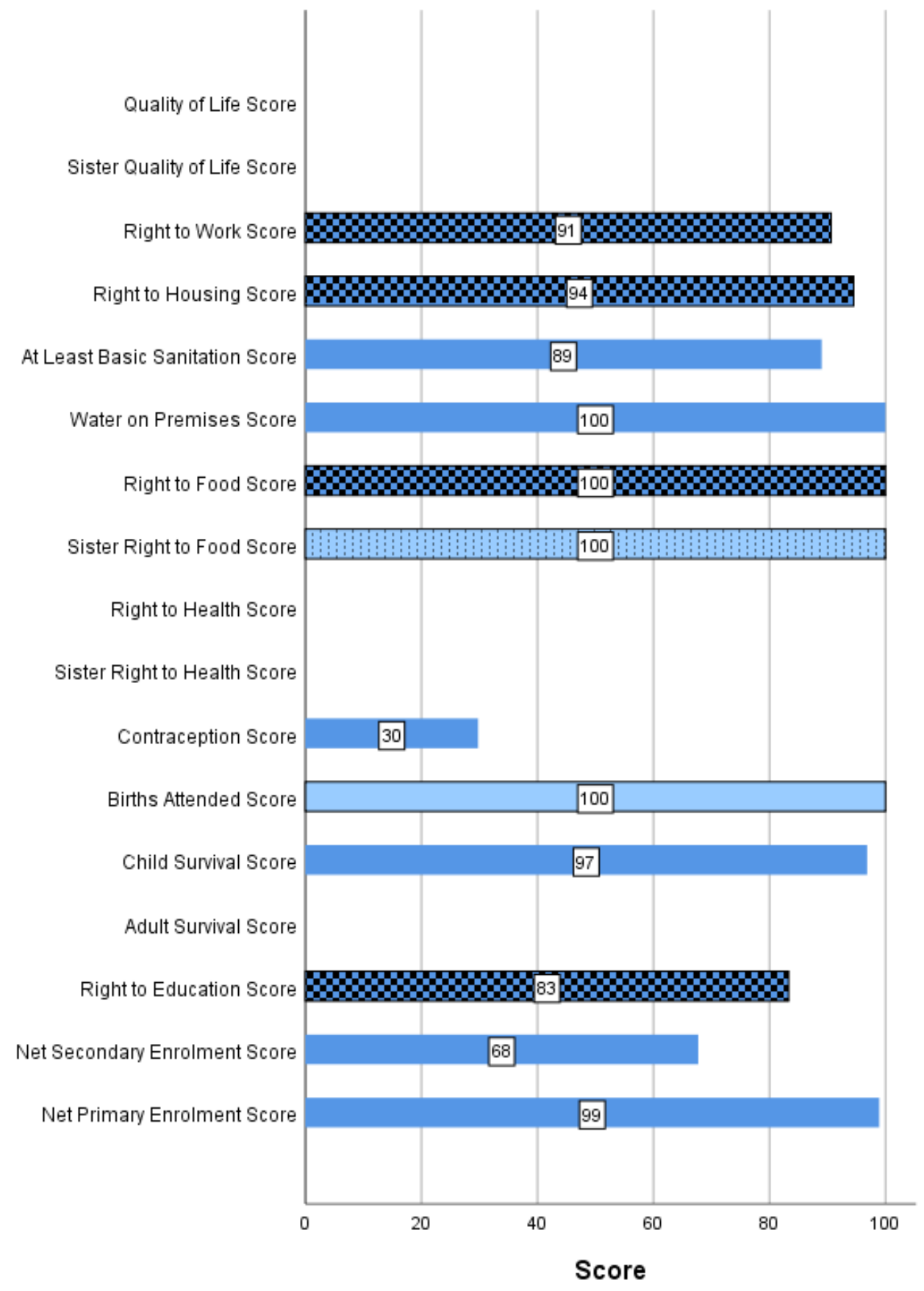

\section{Vanuatu: Indicator, right and quality of life scores}

Vanuatu does an excellent job of ensuring child and adult health given its resources (figure 12). As is the for most pacific countries, it while it does a good job of ensuring women have access to healthcare during childbirth, its performance is very poor when it comes to ensuring couples have access to consistent reproductive health care. As a result, its score on the Sister Right to Health metric is excellent, but its score on the standard Right to Health metric is poor. Similar to most Pacific countries Vanuatu does 
a good job of ensuring people have food with enough calories, but the nutritional quality of that food is not sufficient to ensure optimal child growth. The area where Vanuatu has the greatest potential to improve rights enjoyment is the Right to Housing; even without further per capita income growth, it should be able to substantially extend the necessary infrastructure to provide its people with improved water and sanitation.

\section{Samoa: Indicator, right and quality of life scores}

With a score of 90 on our overall Quality of Life metric, Samoa is doing a fair job of translating its resources into rights enjoyment as can be seen from figure 13. Its performance is particularly strong on the Right to Food and the Right to Housing. It scores 100 on both our standard Right to Food metric and the Sister Right to Food metric indicating that it is setting the benchmark for its income level on both the caloric and nutritional adequacy of food enjoyed by its people. It similarly sets the benchmark for its income level on ensuring housing provides at least "basic" sanitation infrastructure and does a good job of ensuring households have improved water on the premises. While its score on the Right to Education is only fair, at 86, it has succeeded in ensuring universal primary education. Samoa's area of weakness is ensuring couples have access to reproductive health services. Samoa's scores badly on ensuring women have access to health care during childbirth and very poorly on ensuring couples have consistent access to reproductive health care. It is in this latter area that Samoa has the potential to do much, much better even without increasing its per capita income. 
Figure 12 Vanuatu Indicator and Right Scores: Income Adjusted Benchmark, Low- and MiddleIncome Assessment Standard

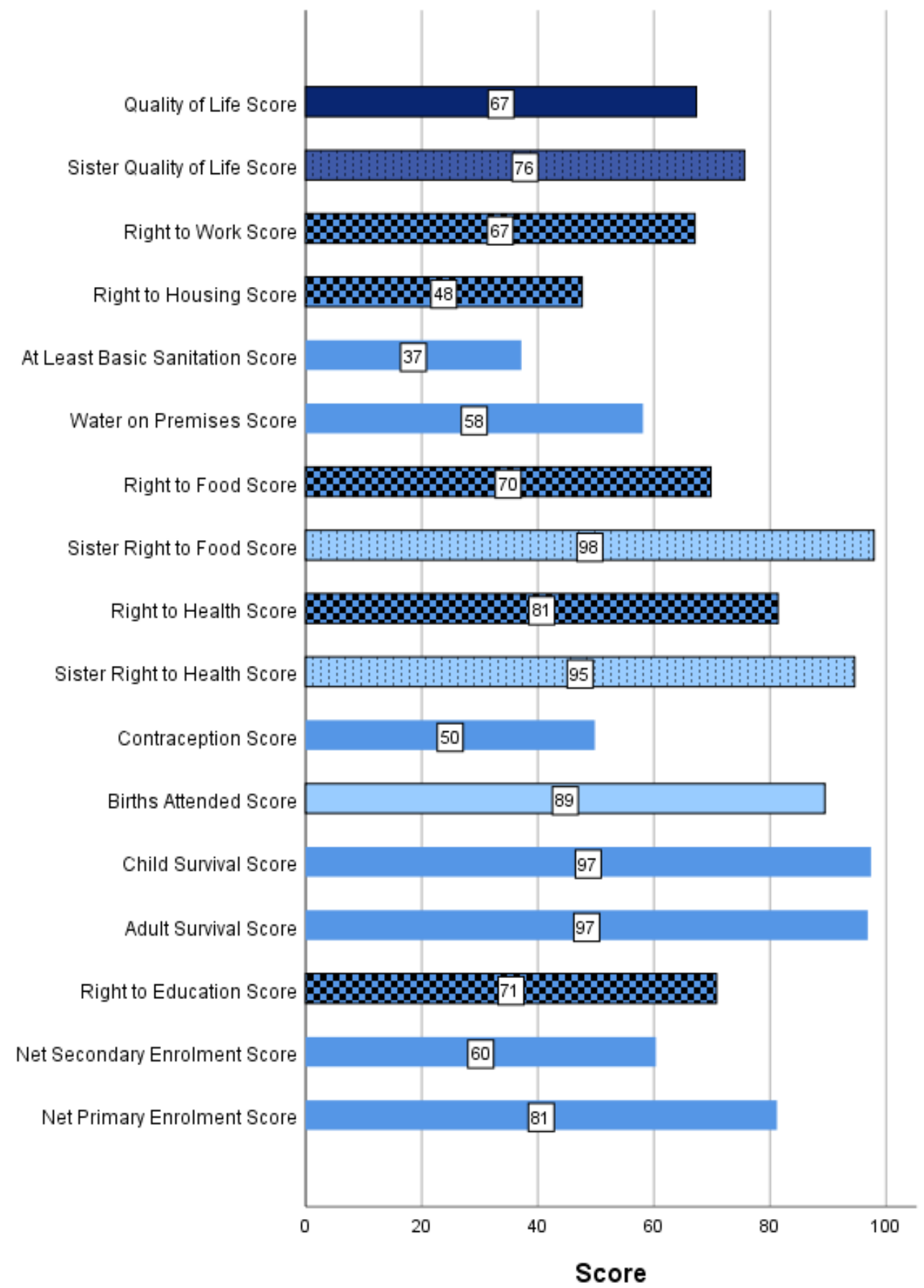


Figure 13: Samoa Indicator and Right Scores: Income Adjusted Benchmark, Low- and MiddleIncome Assessment Standard.

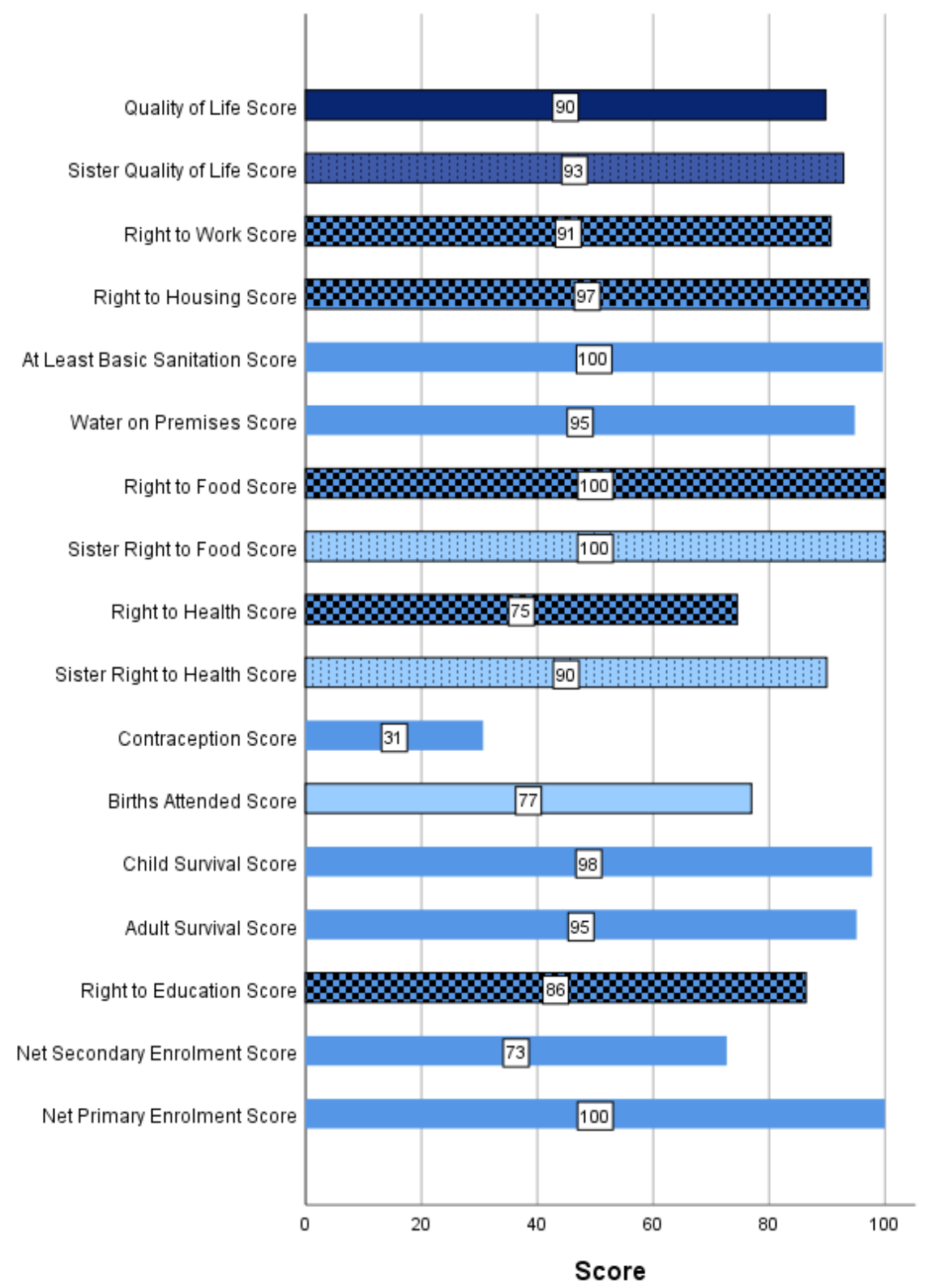

\section{Comparison Country Performance}

The country by country review of economic and social right performance in the Pacific suggested that although for some rights, performance varied widely across the Pacific, there were also some common strengths and weaknesses. Here we draw out those differences as well as the common areas of strength and weaknesses.

\section{Right to Education}

There is substantial variation across the Pacific in people's enjoyment of their Right to Education. The challenge is greatest when it comes to ensuring access to secondary education, although for some countries there is tremendous scope to improve access to 
primary education within the constraints of their current resources. The difference between the percentage of the income adjusted benchmark achieved for primary and secondary education ranges from 2 percentage points (Vanuatu) to 43 percentage points (Micronesia) and averages 19 percentage points. Only in Tonga is the score higher for secondary education than primary education.

There is also variation within countries in the extent to which females and males are able to claim their right to education. Figures 14 and 15 compare performance across the Pacific on the Right to Education for females and males, respectively. As can be seen, the scores for females range from $45 \%$ of the income adjusted benchmark for Papua New Guinea to $100 \%$ of the benchmark for Kiribati. The range in scores for males is somewhat smaller, $52 \%$ to $91 \%$ of the benchmark. Perhaps somewhat surprisingly, the Right to Education scores are higher for females than males in every country except Papua New Guinea and the Solomon Islands. The gap is not, however extremely wide; it ranges from 2 to 11 percentage points.

Figure 14: Country Comparison: Right to Education, Females—Income Adjusted Benchmark, Low- and Middle- Income assessment Standard.

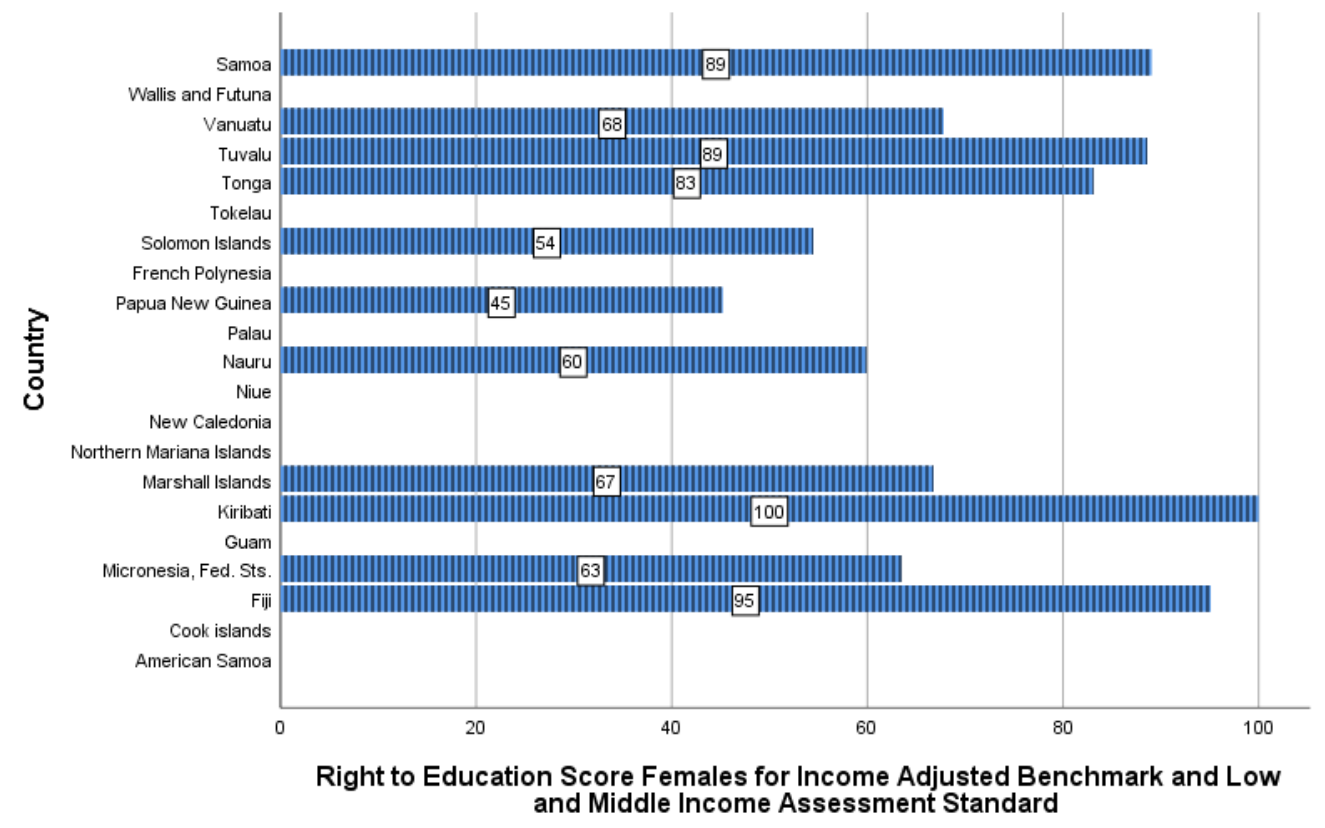


Figure 15: Country Comparison: Right to Education, Males—Income Adjusted Benchmark, Low- and Middle- Income assessment Standard

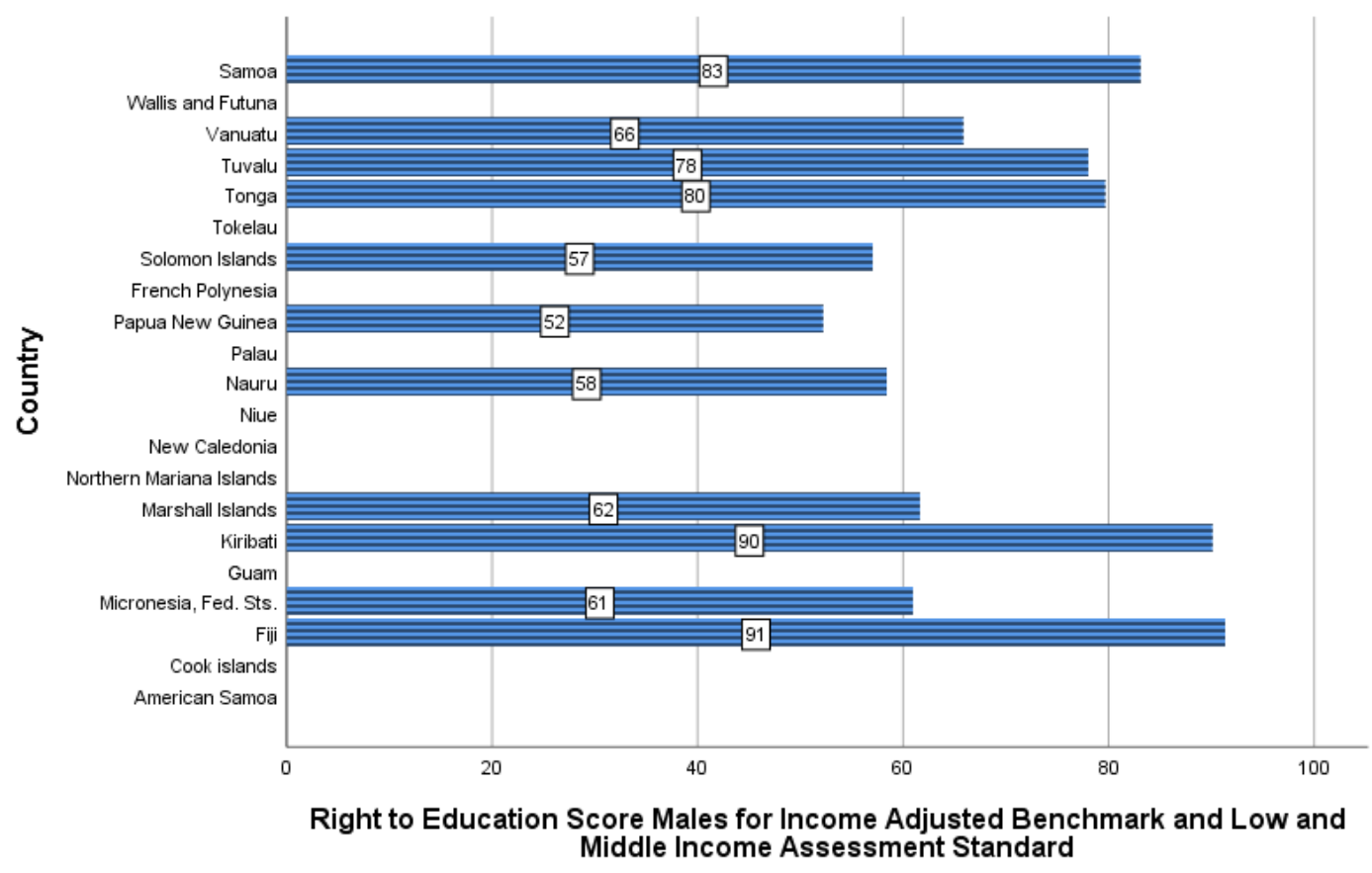

\section{Right to Health}

Scores on the Right to Health tend to be more similar across countries than scores on the Right to Education, but with the exception of Micronesia, fall in the bad to very bad range as can be seen from figure 16 . However, the challenge lies primarily with ensuring access to reproductive health, and within that dimension, reproductive health care that extends beyond ensuring women have access to skilled health professionals during childbirth. This can be seen from figure 17 which compares the country scores on our Sister Right to Health measure. As will be recalled, the Sister Right to Health metric differs from our standard Right to Health metric in that the reproductive health indicator is changed; the percentage of births attended by skilled health professionals is substituted for the modern contraceptive prevalence rate. When this is done, virtually all of the Pacific countries' scores rise dramatically to the fair to good range. The Pacific country scores on the contraceptive use rate for all Pacific countries, except for Micronesia, are simply exceptionally poor. One caveat that bears further explanation is whether in the Pacific context, factors other than lack of consistent access to reproductive health care dominate couples' decision not to use modern contraceptive methods. 
Figure16. country comparison: Right to Health—Income Adjusted Benchmark, Low- and Middle- Income Assessment Standard.

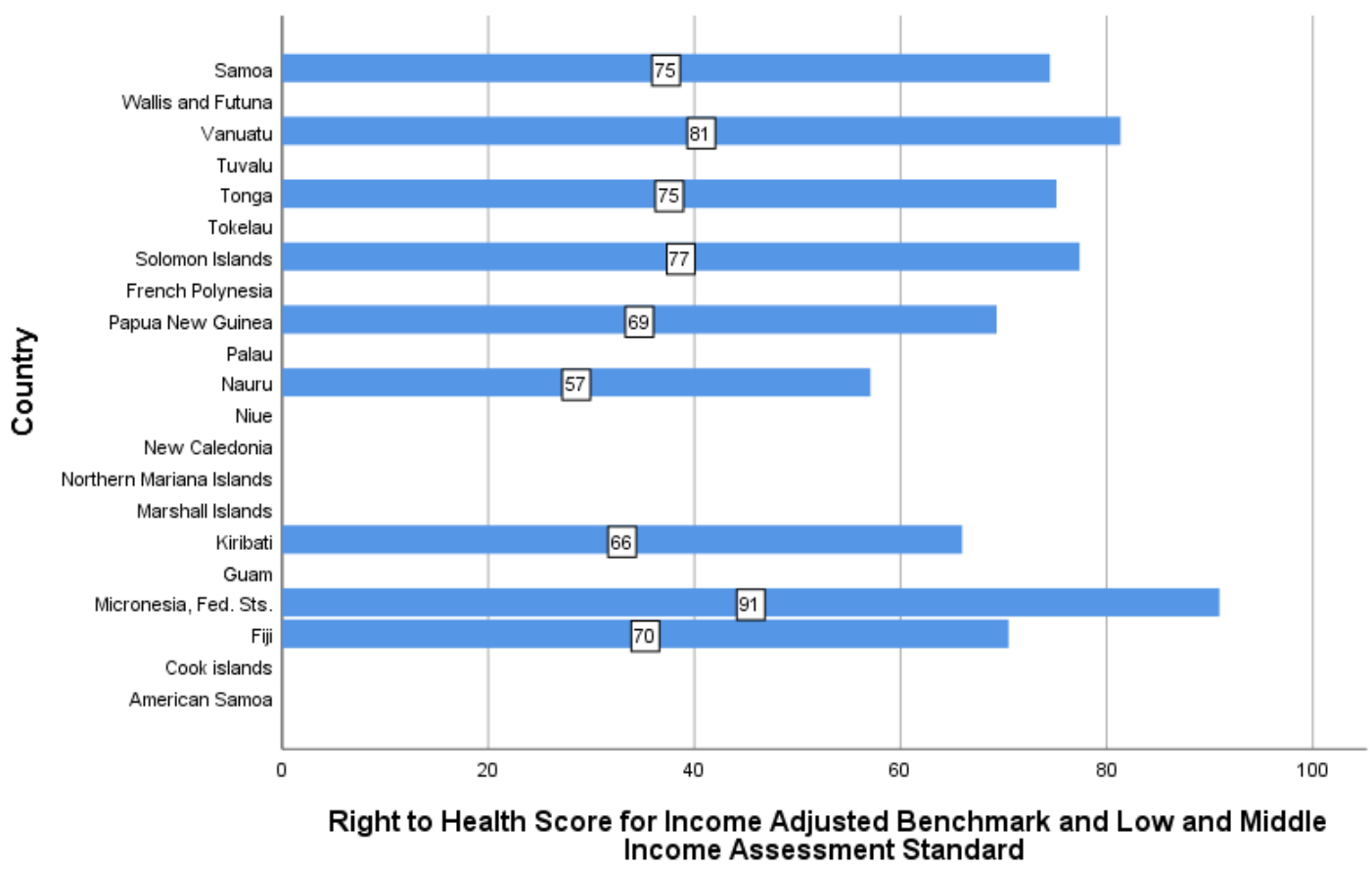

Figure 17: Country Comparison: Sister Right to Health—Income Adjusted Benchmark, Low- and MiddleIncome Assessment Standard

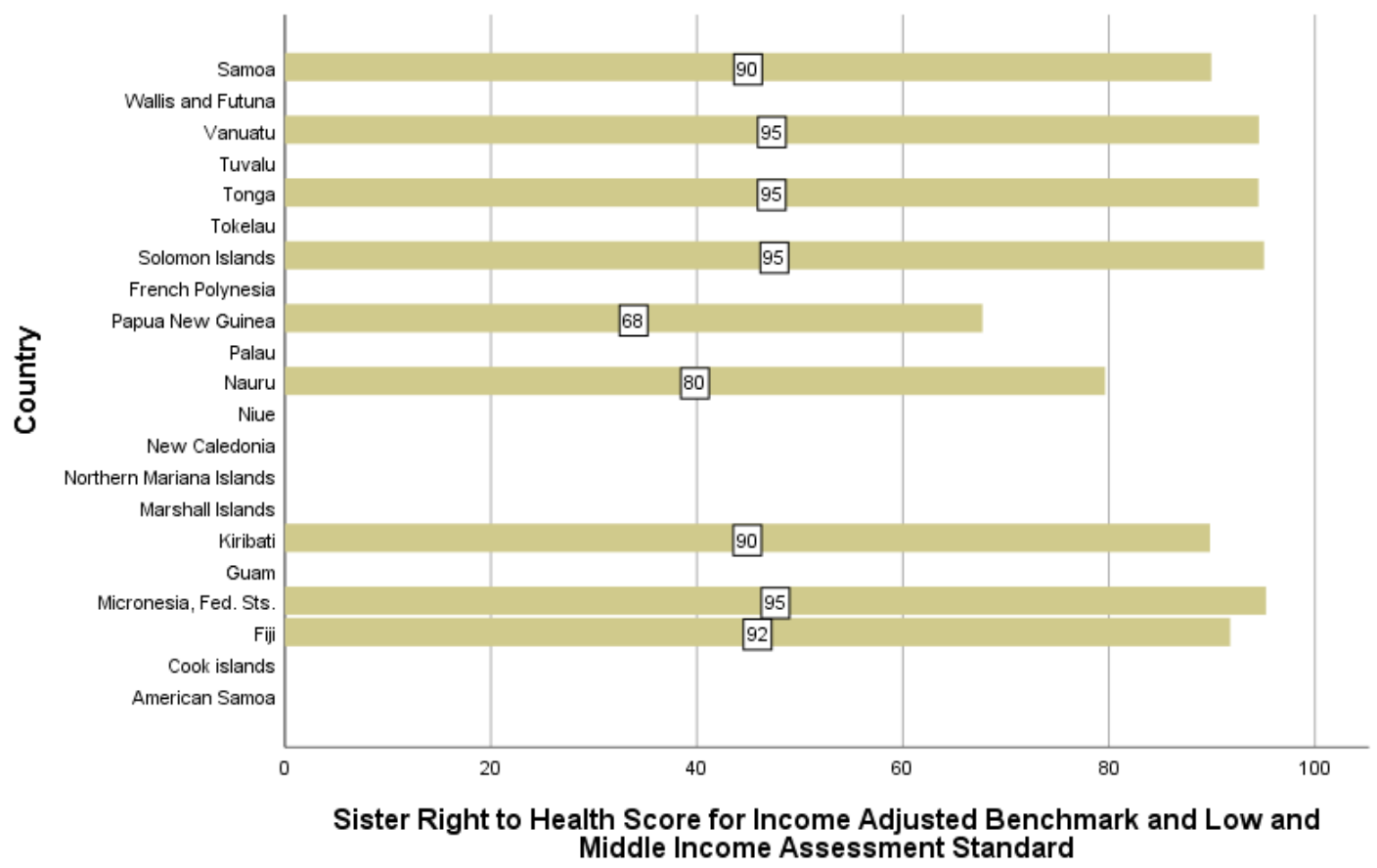

\section{Right to Food}

Another consistent finding in the Pacific is that while child stunting, the absence of which is our bellwether indicator of the Right to Food, remains a significant problem in the Pacific the problem resides with the protein and micro-nutrient value of foods consumed rather than the caloric content of food consumed. Our Sister Right to Food indicator uses an indicator of the caloric adequacy of food available to households (100\% - the "undernourishment rate") instead of the percentage of children that are not 
stunted. As figure 18 shows, virtually all of the Pacific countries set the global income adjusted benchmark for their per capita income level. Comparing the country scores on the Sister Right to Food metric (figure 18) with those for our standard right to Food metric (figure 19) shows stark differences in performances. Although three countries (Samoa, Tuvalu, and Tonga) score virtually identically on the two metrics the differences in the scores for the other countries are large: 24 percentage points for Vanuatu, and the Solomon Islands, 27 for Nauru, 43 for the Marshall Islands, and 58 for Papua New Guinea. The difference in the scores on the Sister Right to Food metric and our standard Right to Food metric may reflect more than the nutritional quality of the food consumed. There are interactions between rights. In those Pacific countries with low scores on our standard Right to Food metric, challenges in ensuring the rights to water and sanitation may well be contributing to the gap. We turn now to the question of whether housing infrastructure ensures the rights to water and sanitation.

Figure 18: Country Comparison: Sister Right to Food-Income Adjusted Benchmark, Low- and MiddleIncome Assessment Standard

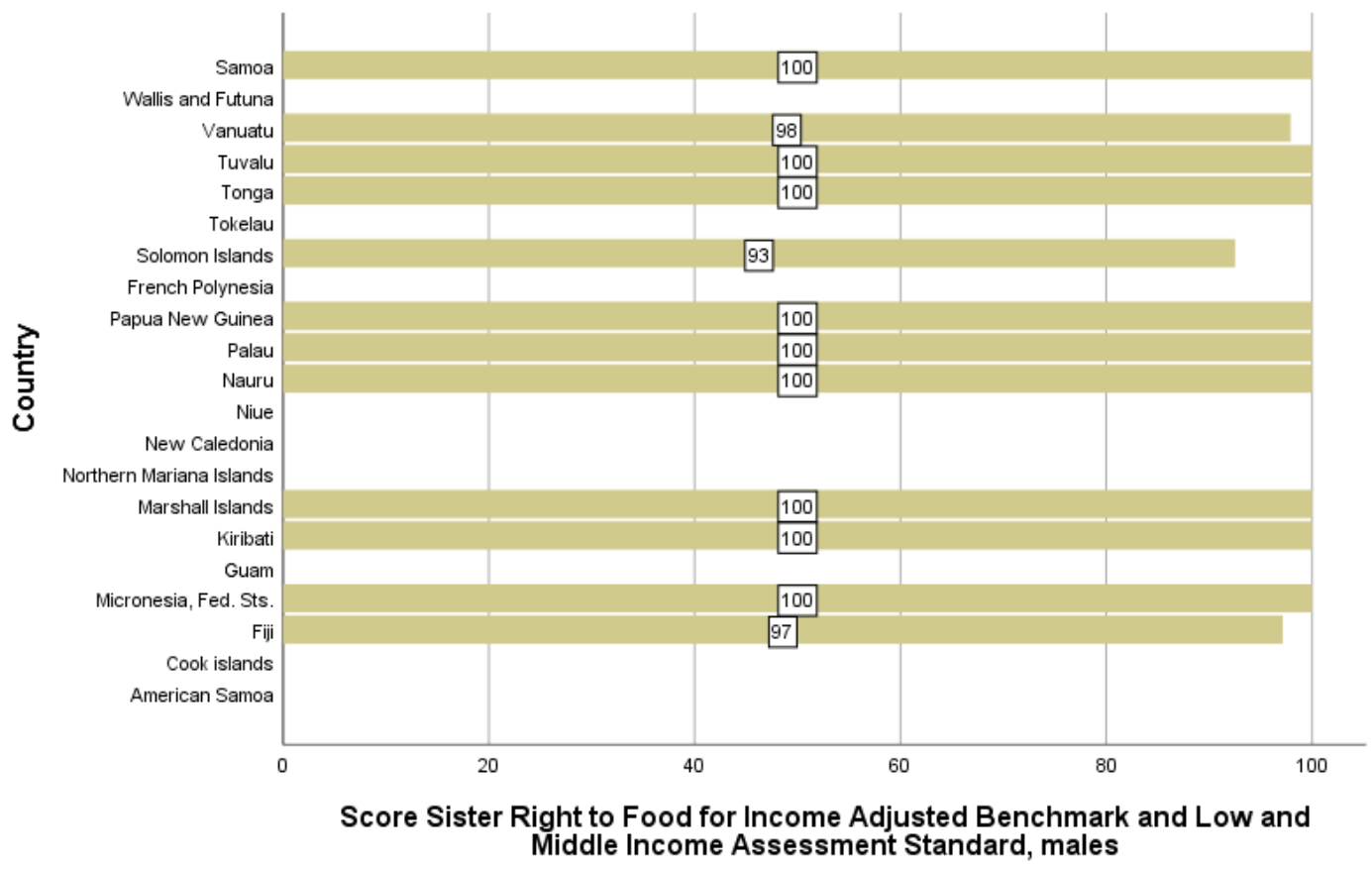


Figure 19: Country Comparison: Right to Food-Income Adjusted Benchmark, Low- and Middle- Income Assessment Standard.

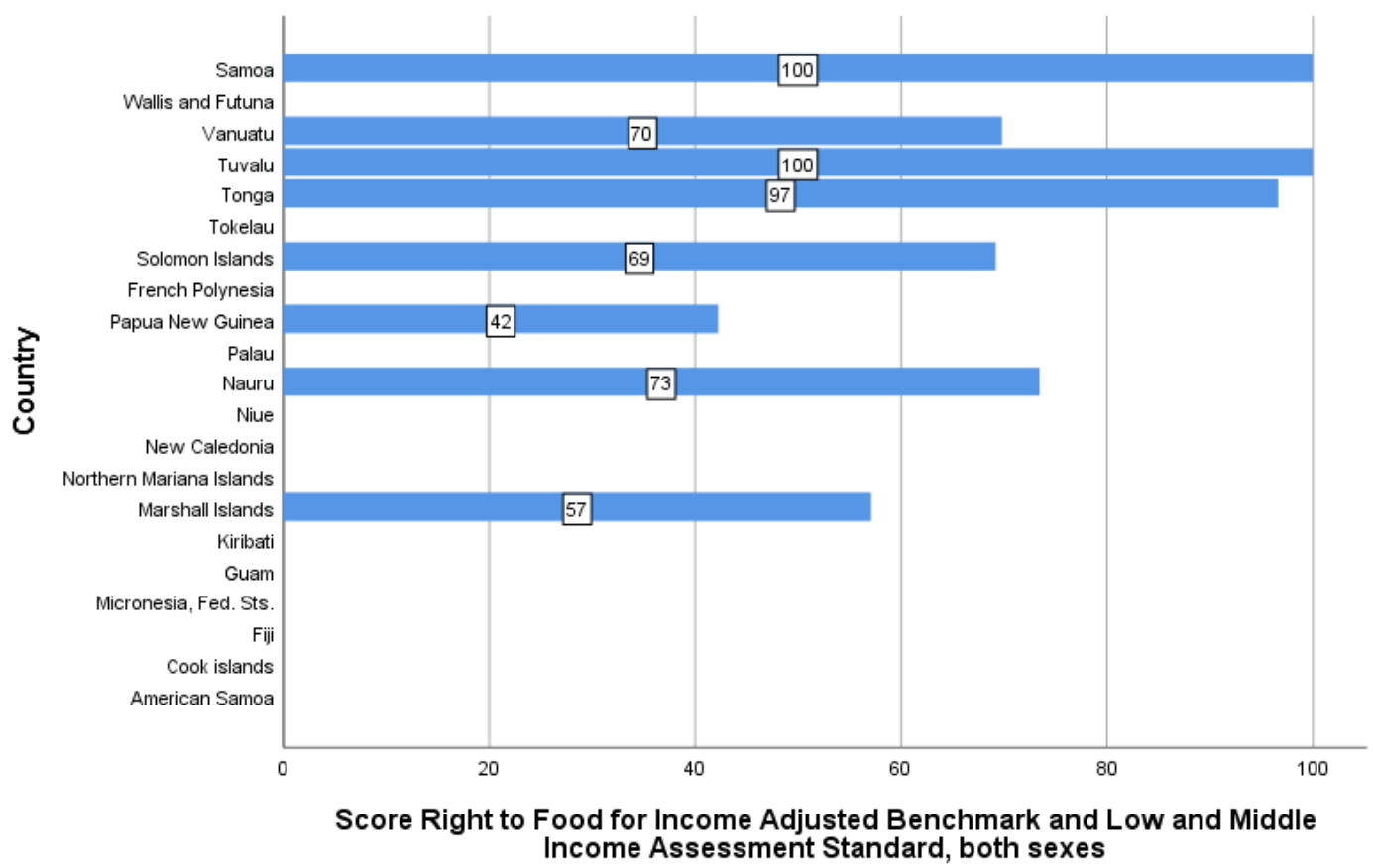

\section{The Right to Housing}

Country scores on the Right to Housing are shown in figure 20 below. It should be recalled that at this time, data availability only enables us to capture the infrastructure aspect of the right to housing in this metric, specifically water and sanitation infrastructure. As speculated above, the country scores provide some evidence of an interaction with our standard Right to Food metric. Among the countries that score well on the Right to food, Samoa, Tuvalu and Tonga, two, Samoa and Tuvalu score above $90 \%$ on the Right to Housing, while Tonga's score is 83 . As for countries facing the greatest challenge to ensure the right to nutritious food, Solomon Islands, Papua New Guinea, and Marshall Islands, the first two also score badly on the Right to Housing, 53 and 18 respectively. The Marshall Island's in contrast scores in the middle of the fair range, 90 on the Right to Housing so its challenge related to ensuring access nutritious food is not likely importantly influenced by the Right to Housing. Overall, country performance on the Right to Housing varies widely across the Pacific with countries achieving between 18 and $100 \%$ of what should be feasible given their per capita income level. 
Figure 20: Country Comparison—Right to Housing, Income Adjusted Benchmark, Low- and MiddleIncome Assessment Standard

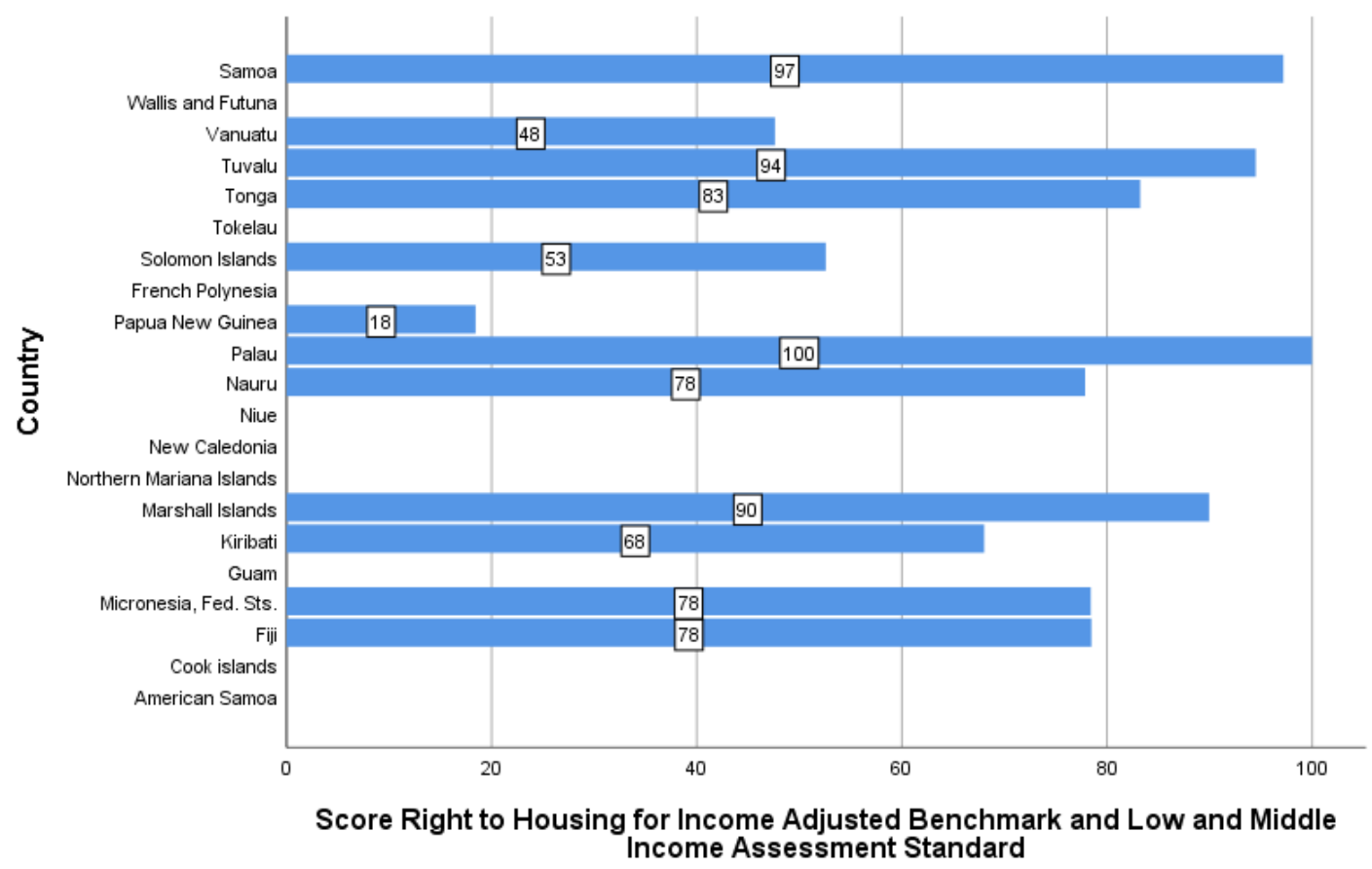

\section{The Right to Work}

Our standard metric of the Right to Work focuses on whether people have access to sufficient well-paying work to avoid absolute poverty. Among the countries we have data on, results vary widely. Samoa, Tuvalu and Tonga achieve over $90 \%$ of what is reasonably feasible given their per capita income level, while the Solomon Islands and Papua New Guinea should be able to ensure that at least twice as many people are able to avoid absolute poverty (figure 21) even in the absence of per capita income growth. The remaining three countries, Vanuatu, Micronesia and Fiji fall between the two groups. 
Figure 21: Country Comparison—Right to Work, Income Adjusted Benchmark, Low- and Middle- Income Assessment Standard

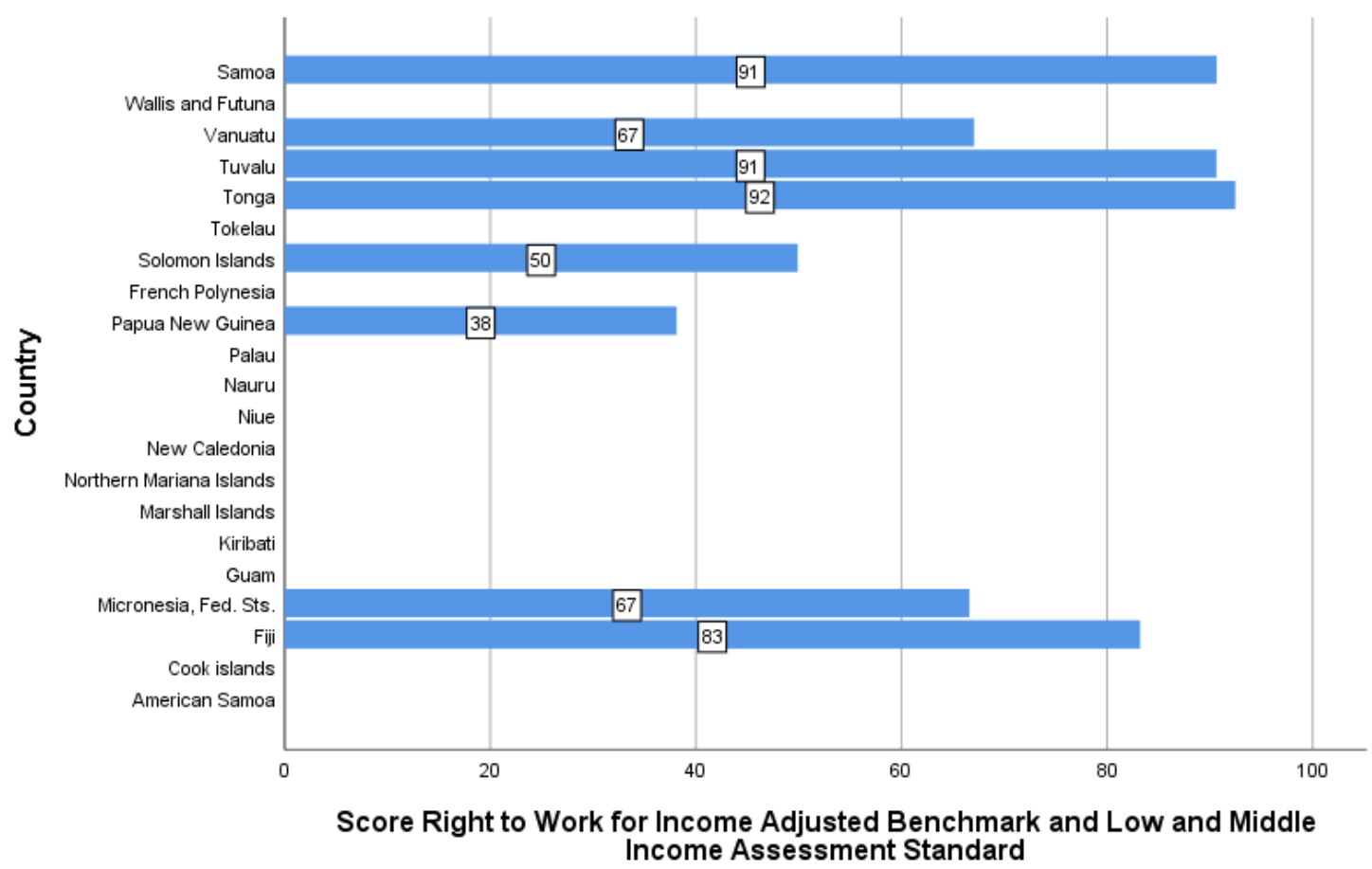

\section{Quality of Life}

We are able to compute Quality of Life Scores using the Income Adjusted Benchmark for the Low- and Middle- Income Assessment Standard for 5 countries using our standard rights metrics and for 7 countries substituting in the "sister right" scores for standard right scores on the Right to Food and the Right to Health. The results are shown in figures 22 and 23. The scores for the 5 countries that both the Quality of Life and Sister Quality of Life scores can be computed for are higher by 3 to 11 percentage points depending on the country, on the Sister Quality of Life metric. Regardless of which metric is used, it is clear that there are opportunities to substantially improve well-being in the Pacific even in the absence of per capita income growth. Given the range in scores there is also considerable scope for countries to learn from each other what approaches hold promise-countries scoring poorly on one right can look to the policies and structures in place that have enabled other countries to achieve good scores on the same right. While lessons from other Pacific countries are likely to be most readily transferable, there are undoubtably lessons that can be drawn from countries beyond the Pacific. The performance of countries beyond the Pacific can be viewed at our rightstracker site. 
Figure 22: Country Comparison: Quality of Life Score-Income Adjusted Benchmark, Low- and MiddleIncome Assessment Standard.

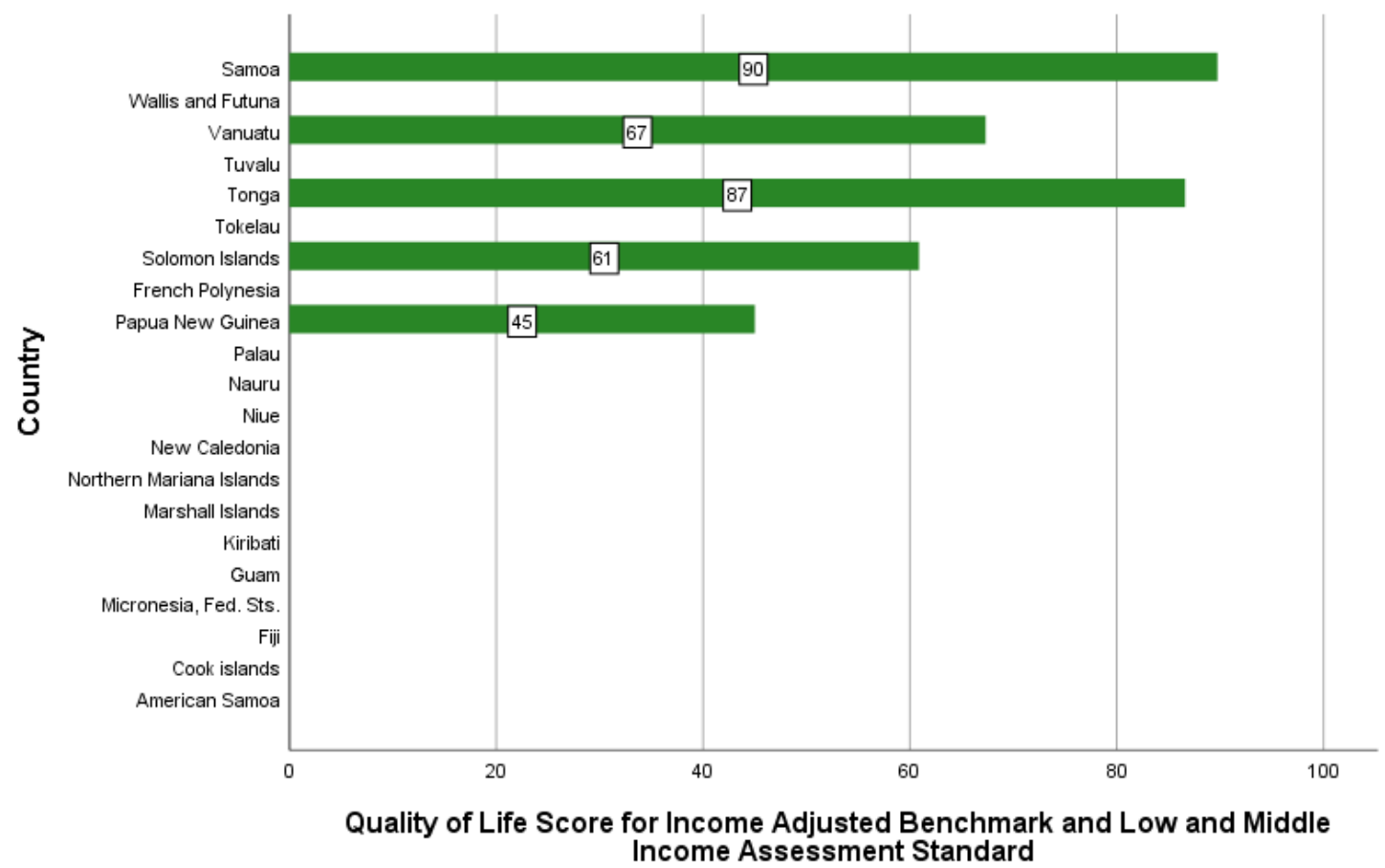

Figure 23: Country Comparison: Sister Quality of life Score, Income Adjusted Benchmark, Low- and MiddleIncome Assessment Standard.

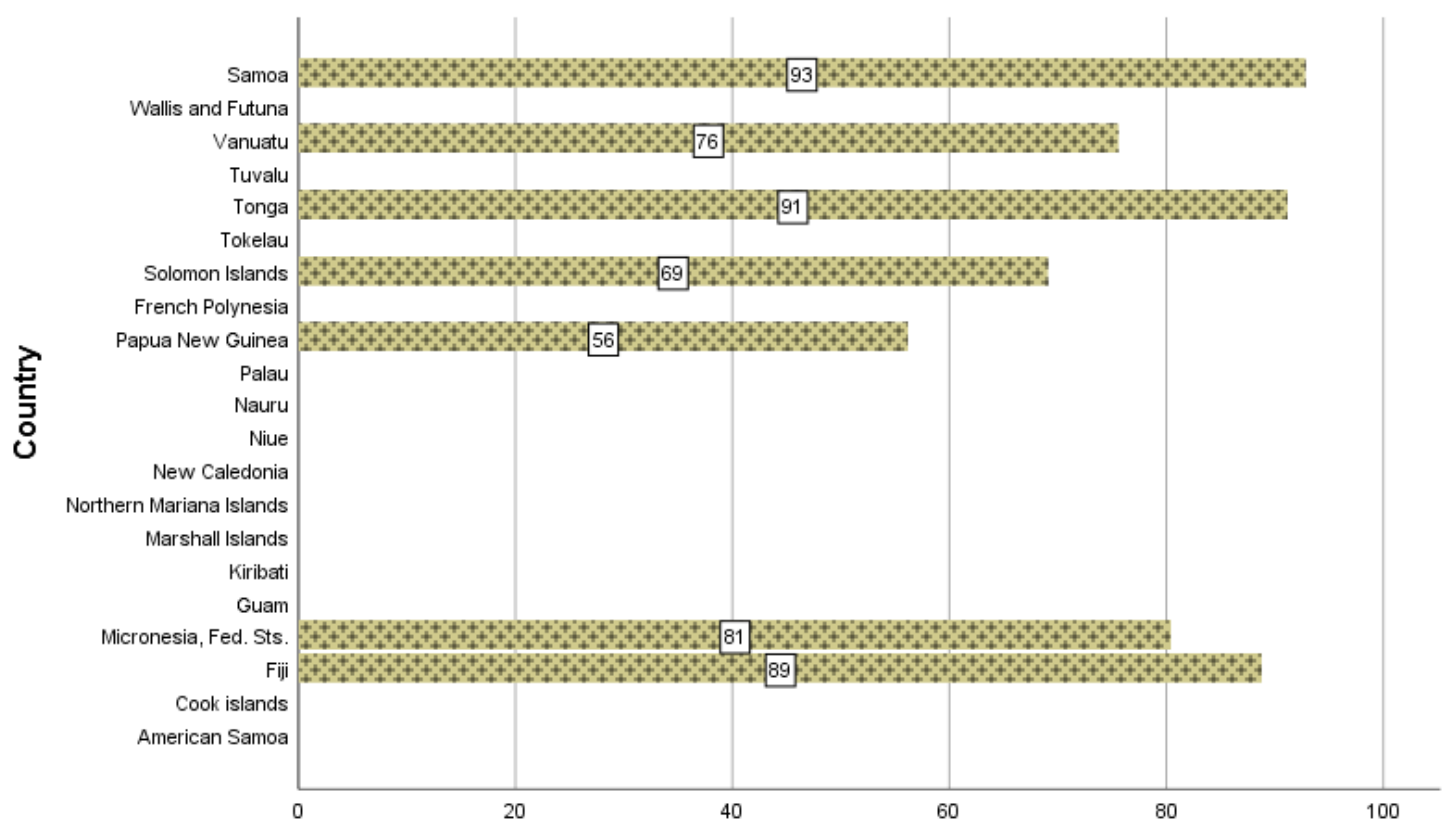

SisterQuality of Life Score for Income Adjusted Benchmark and Low and Middle Income Assessment Standard 


\section{B. Exploring the Bias When Country Gross National Income Exceeds Gross Domestic Product}

Our standard measure of a country's resource capacity is Gross Domestic Product (GDP) per capita measured in 2011 PPP\$. However, an alternative measure is Gross National Income (GNI) per capita measured in 2011 PPP\$. For most countries there is little difference between the two measures. However, for several of the Pacific countries it does matter and there is a sizable difference between the two measures. Table 3 below shows the ratio between the two indicators for those countries in the Pacific for which both indicators are available. For 5 of the 12 Pacific countries with data, Kiribati, Tuvalu, Marshall Islands, the Federated States of Micronesia, and Nauru the difference is far from trivial. These countries' GDP per capita understates the resources available to them to ensure economic and social rights.

Table 3: Ratio of GNI per capita (2011 PPP\$) to GDP per capita (2011 PPP\$)

$\begin{array}{llll}\text { Country } & \begin{array}{l}\text { GDP per capita } \\ (2011 \text { PPP\$) }\end{array} & \begin{array}{l}\text { GNI per capita } \\ (2011 \text { PPP\$) }\end{array} & \text { Ratio GNI/GDP } \\ \text { Fiji } & 9389 & 8817 & 0.939 \\ \text { Kiribati } & 2025 & 3972 & 1.96 \\ \text { Marshall Islands } & 3437 & 4504 & 1.31 \\ \text { Micronesia, Fed. St. } & 2752 & 3608 & 1.31 \\ \text { Nauru } & 13670 & 17342 & 1.27 \\ \text { Palau } & 16239 & 17061 & 1.05 \\ \text { Papua New Guinea } & 3957 & 3881 & 0.981 \\ \text { Samoa } & 5904 & 5717 & 0.968 \\ \text { Solomon Islands } & 2125 & 2026 & 0.953 \\ \text { Tonga } & 5746 & 5835 & 1.02 \\ \text { Tuvalu } & 3548 & 5072 & 1.43 \\ \text { Vanuatu } & 2839 & 2808 & 0.989\end{array}$

When a country's GNI per capita exceeds its GDP per capita its ESR scores will be biased upward, and this bias is potentially quite large for the Income Adjusted Benchmark. This is because the benchmark against which the country's indicator value is compared will be higher when assessed using GNI per capita, the actual level of resources available to the country, than when using GDP per capita.

To gain insight into the extent of this bias, we recalculated HRMI's ESR metrics using GNI per capita (2011 PPP\$) for the Pacific countries using the Income Adjusted Benchmark and the Low- and Middle- Income Assessment Standard. The results are 
compared in tables A1. through A10. of Appendix A. As expected, in many cases indicator and right scores are higher when GDP per capita (2011 PPP\$) is used as the measure of a country's resources than when GNI per capita (2011 PPP\$) is use. In a number of cases the differences is small, but in others it is quite large. We consider a bias of 3 percentage points or more to be substantively important because this amount can readily move a country from one performance category to another, for example from good to fair. Table 4 below compiles from Appendix A those cases where the use of our standard per capita income indicator, GDP per capita (2011 PPP\$), results in an upward bias of three percentage points or more.

Table 4. Pacific countries where the use of GDP per capita (2011 PPP\$) instead of GNI per capita (2011 PPP\$) biases the scores by 3 percentage points or more.

Indicator/Right
Net primary Ed, both sexes
Net Sed Ed, both sexe
Right to Education, both sexes
Adult Survival, both sexes
Child Survival, both sexes
Modern Contraception
Right to Health
Births Attended
Sister Right to Health
Water on Premises
Basic Sanitation
Right to Housing
Not Stunted/Right to Food, both sexes
Enough Calories/Sister Right Food
Not Absolutely Poor/ Right to Work
Quality of Life
Sister Quality of Life

\section{Countries and percentage point upward bias}

Marshall Islands. 3.67

Kiribati 13.67, Marshall Islands 3.25,

Tuvalu 3.67

Kiribati 8.05, Marshall Islands 3.5

Kiribati 5.61

Kiribati 3.94

None

Kiribati 3.56

None

Kiribati $\mathbf{3 . 8 1}$

Kiribati 15.46, Marshall Islands 4.9

Kiribati -5.88, Nauru -3.89

Kiribati 10.68, Marshall 3.62

Tuvalu 6.75

None

Tuvalu 6.94

None

None

The tables in Appendix A confirm that when GNI per capita (2011 PPP\$) exceeds GDP per capita, if the ESR scores are calculated using GDP per capita (2011 PPP\$), the results are biased upward. As Table 4 shows, this bias is substantively important for virtually all indicators and rights in the case of Kiribati and for some indicators and rights in the cases of the Marshall Islands, Tuvalu, and Nauru. These are all countries where their per capita GNI (2011 PPP\$) is at least 1.2 times their per capita GDP (2011 PPP\$). 


\section{When PPP income data are not available for countries, is it reasonable to use USD income data?}

Neither PPP\$ GDP per capita nor PPP\$ GNI per capita data are available for 9 of the 21 Pacific countries. These countries include most of the high-income countries/territories in the Pacific. USD data are available for most of these countries/territories. We sought to explore whether it made any sense to compute the ESR metrics using USD per capita income data in those cases where PPP\$ data are not available. To make the data as comparable as possible, we converted USD per capita GDP data measured in 2010 USD to 2011 USD.

Our expectation was that there was likely to be a substantively important difference in the scores for the two income measures when using the Income Adjusted benchmark since the benchmark increases with a country's per capita income level. However, we thought that the difference might be minimal when using the global best benchmark because then the benchmark is constant. In the case of the global best benchmark we anticipated the main impact on a country's score would be the result of any penalty imposed, and accordingly would likely be highest for high income countries. We also anticipated that the difference could be substantively important in those cases where the income adjusted benchmark reaches its peak at a low per capita income level.

We recalculated all the indicator and rights scores using GDP per capita measured in 2011 USD and compared the results with those using GDP per capita measured in 2011 PPP\$. The results are shown in Tables B.1 through B.13 of Appendix B. Table 5 below identifies those cases where we could compute the indicator and right scores using both income variants and the difference in the scores was greater than 3 percentage points, an amount we feel is substantively important. As expected, the differences between the scores using the per capita GDP (2011 PPP\$) versus per capita GDP (2011 USD) were smaller for the Global Best benchmark, but in a number of cases remained substantively important. Although the differences were larger for the Income Adjusted benchmark, they were not as large as we had initially anticipated. In fact, for a number of the indicators the difference in scores never exceeded 3 percentage points. That being said, among the countries with data on both income variants, only Palau is a highincome country. The bias is likely to be higher for high income-countries. 
Table 5: Pacific countries where the rights scores calculated using GDP per capita measured in 2011 USD exceed those using GDP per capita measured in 2011 PPP\$ by more than 3 percentage points

\section{Indicator/Right}

Net primary Ed, both sexes

Net Sed Ed, both sexes

Right to Education, both sexes

Adult Survival, both sexes

Child Survival, both sexes

Modern Contraception

Right to Health

Births Attended

Sister Right to Health

Water on Premises

Basic Sanitation

Right to Housing

Not Stunted/Right to Food,

both sexes

Enough Calories/Sister Right

Food

Not Absolutely Poor/ Right to

Work

Quality of Life

Sister Quality of Life
Income Adjusted difference GDP per capita USD - PPP\$

Palau 4.10

Fiji 4.49, Samoa 3.56, Solomon Islands 3.68

Solomon Islands 3.09

None

None

None

None

Papua New Guinea 4.47,

Samoa 3.42

None

Fiji 7.22, Samoa 5.22, Solomon Islands 6.59

None

Fiji 4.76, Solomon Islands 4.35

Solomon Islands $\mathbf{4 . 0 2}$

None

Fiji 4.39, Samoa 4.73, Solomon Islands 3.67

Solomon Islands 3.28

None
Global Best difference GDP per capita USD - PPP\$

Palau 4.10

None

None

None

None

None

None

Papua New Guinea 4.47,

Samoa 3.42

None

Fiji 6.71

None

Fiji 3.57

None

None

None

None

None

The benefit of using the USD variant of per capita income is that country coverage can be expanded. Table 6 shows the countries gained by indicator and right. In the case of the Right to Housing and its component ESR scores, this allows us to include all 21 Pacific countries. The gains in country coverage are not as extensive in the case of the rights to Education, Health, and Food and their component indicators. The computation of a USD variant of our metrics allows us to gain some insight, albeit imperfect, into several aspects of ESR performance for a number of additional Pacific countries. 
Table 6: Countries gained from using GDP per capita measured in 2011 USD instead of 2011 PPP\$.

\begin{tabular}{|c|c|c|}
\hline Indicator/Right & $\begin{array}{l}\text { Number } \\
\text { Countries } \\
\text { Gained }\end{array}$ & Countries Gained \\
\hline Net primary Ed, both sexes & 5 & Cook Islands, French Polynesia, Guam, Niue, Tokelau \\
\hline Net Sed Ed, both sexes & 3 & Cook Islands, Niue, Tokelau \\
\hline Right to Education, both sexes & 3 & Cook Islands, Niue, Tokelau \\
\hline Adult Survival, both sexes & 7 & $\begin{array}{l}\text { American Samoa, Cook Islands, French Polynesia, } \\
\text { Guam, New Caledonia, Niue, Northern Mariana } \\
\text { Islands }\end{array}$ \\
\hline Child Survival, both sexes & 8 & $\begin{array}{l}\text { American Samoa, Cook Islands, Guam, New } \\
\text { Caledonia, Niue, Northern Mariana Islands, Tokelau, } \\
\text { Wallis \& Futuna }\end{array}$ \\
\hline Modern Contraception & 1 & Northern Mariana Islands \\
\hline Right to Health & 1 & Northern Mariana Islands \\
\hline Births Attended & 7 & $\begin{array}{l}\text { American Samoa, Cook Islands, Guam, New } \\
\text { Caledonia, Niue, Northern Mariana Islands, Tokelau }\end{array}$ \\
\hline Sister Right to Health & 6 & $\begin{array}{l}\text { American Samoa, Cook Islands, Guam, New } \\
\text { Caledonia, Niue, Northern Mariana Islands }\end{array}$ \\
\hline Water on Premises & 9 & $\begin{array}{l}\text { American Samoa, Cook Islands, French Polynesia, } \\
\text { Guam, New Caledonia, Niue, Northern Mariana } \\
\text { Islands, Tokelau, Wallis and Futuna }\end{array}$ \\
\hline Basic Sanitation & 9 & $\begin{array}{l}\text { American Samoa, Cook Islands, French Polynesia, } \\
\text { Guam, New Caledonia, Niue, Northern Mariana } \\
\text { Islands, Tokelau, Wallis and Futuna }\end{array}$ \\
\hline Right to Housing & 9 & $\begin{array}{l}\text { American Samoa, Cook Islands, French Polynesia, } \\
\text { Guam, New Caledonia, Niue, Northern Mariana } \\
\text { Islands, Tokelau, Wallis and Futuna }\end{array}$ \\
\hline $\begin{array}{l}\text { Not Stunted/Right to Food, } \\
\text { both sexes }\end{array}$ & 1 & New Caledonia \\
\hline $\begin{array}{l}\text { Enough Calories/Sister Right } \\
\text { Food }\end{array}$ & 4 & $\begin{array}{l}\text { Cook Islands, French Polynesia, New Caledonia, } \\
\text { Niue }\end{array}$ \\
\hline $\begin{array}{l}\text { Not Absolutely Poor/ Right to } \\
\text { Work }\end{array}$ & $\mathbf{0}$ & \\
\hline Quality of Life & 0 & \\
\hline Sister Quality of Life & 0 & \\
\hline
\end{tabular}

